\title{
Measuring Financial Inclusion: Explaining Variation in Use of Financial Services across and within Countries
}

ABSTRACT This paper summarizes the first publicly available, user-side data set of indicators that measure how adults in 148 countries save, borrow, make payments, and manage risk. We use the data to benchmark financial inclusion - the share of the population that uses formal financial services-in countries around the world, and to investigate the significant country- and individual-level variation in how adults use formal and informal financial systems to manage their day-to-day finances and plan for the future. The data show that 50 percent of adults worldwide are "banked," that is, have an account at a formal financial institution, but also that account penetration varies across countries by level of economic development and across income groups within countries. For the half of all adults around the world who remain unbanked, the paper documents reported barriers to account use, such as cost, distance, and documentation requirements, which may shed light on potential market failures and provide guidance to policymakers in shaping financial inclusion policies.

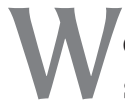

ell-functioning financial systems serve a vital purpose, offering savings, payment, credit, and risk management products to people with a range of needs. More-inclusive financial systems - those that allow broad access to appropriate financial services - are likely to benefit poor people and other disadvantaged groups. For instance, access to formal savings and credit mechanisms may facilitate investment in productive activities such as education or entrepreneurship. Lacking such access, individuals rely on their own limited, informal savings to invest in their education or 
become entrepreneurs, and small enterprises on their limited earnings to take advantage of promising growth opportunities. This can contribute to persistent income inequality and slower economic growth. ${ }^{1}$

This paper benchmarks financial inclusion and explores country- and individual-level variation in how adults around the world use formal and informal financial products to manage their finances and plan for the future. We define financial inclusion as the use of formal financial services, and we investigate how patterns of financial inclusion vary across countries at different levels of income per capita, and within countries at different levels of relative income. Next, we examine the barriers to financial inclusion and document the relationship between subjective and objective barriers to access. Finally, we discuss examples of public and private sector-led initiatives in this realm and how better data can inform policymakers in shaping financial inclusion policies. Although the literature and the data provide suggestive evidence of market failures and of potential welfare gains from greater financial inclusion, we emphasize that the role of our data is to help policymakers better understand the existence of these failures, rather than to advocate specific policy interventions.

Our paper contributes to a growing literature examining household finance and, especially, the borrowing and saving decisions of households. ${ }^{2}$ Qualitative evidence from financial diaries demonstrates that poor people juggle complex financial transactions every day and use sophisticated techniques to manage their finances, irrespective of whether they use formal financial instruments (Collins and others 2009). Evidence from field experiments highlights that people with access to savings accounts or simple informal savings technologies are more likely to increase consumption, productivity and income, and investment in preventive health, and to have reduced vulnerability to illness and other unexpected events (Dupas and Robinson 2009, 2011, Ashraf and others 2010). Yet the evidence from field experiments that increase access to microcredit shows more modest effects in promoting investment and entrepreneurship, mostly for households with existing businesses (Banerjee and others 2010, Karlan and Zinman 2010).

Until now, little was known about the global reach of the financial sector - the extent of financial inclusion worldwide and the degree to which

1. See, for example, King and Levine (1993), Beck, Demirgüç-Kunt, and Levine (2007), Beck, Levine, and Loayza (2000), Demirgüç-Kunt and Levine (2009), Klapper, Laeven, and Rajan (2006), and World Bank (2008a).

2. For a detailed literature review see World Bank (2008a) and the references therein. Campbell (2006) also provides an overview of the household finance field. 
groups such as the poor are excluded from formal financial systems. Systematic indicators on the use of different financial services were lacking for most countries. The Global Financial Inclusion ("Global Findex") database provides such indicators, measuring how adults in 148 countries around the world manage their day-to-day finances and plan for the future. The indicators are constructed using survey data from interviews with more than 150,000 nationally representative and randomly selected adults over the 2011 calendar year. ${ }^{3}$ The individual-level data are publicly available online and include over 40 indicators related to account ownership, payments, saving, borrowing, and risk management. ${ }^{4}$

Consistent with previous findings, the Global Findex data show that the vast majority of adults actively use financial products, formal or informal, to manage their finances and plan for the future. We find that 75 percent of adults worldwide use at least one of the financial management tools included in the Global Findex survey, and half of all adults report having an individual or a joint account at a formal financial institution. These accounts are used for a wide range of purposes including receipt of wage payments, government transfers, and remittances from family members living elsewhere.

At the country level, the Global Findex data show sharp disparities in the use of financial services between high-income and developing countries, confirming the findings of previous studies that show lower use of formal financial services in developing countries (see, for example, Beck, Demirgüç-Kunt, and Martinez Peria 2007 and Cull, Demirgüç-Kunt, and Morduch 2013). For instance, the share of adults in high-income countries who are "banked" (have an account at a formal financial institution) is more than twice that in developing countries.

At the individual level, the data also show significant variation in financial inclusion within countries across individual characteristics such as income. Around the world, wealthier adults tend to make greater use of formal financial services, even after one controls for other individual characteristics and country fixed effects. For instance, in developing countries as a group, adults in the highest 20 percent of income earners are more than twice as likely to have an account as those in the lowest 20 percent.

3. The Bill \& Melinda Gates Foundation funded three triennial rounds of data collection through the complete questionnaire. The next data collection will be in 2014 .

4. The database and the full questionnaire are available at www.worldbank.org/global findex. Appendix A reproduces selected questions relevant to this paper. The questionnaire is also available in 15 languages at go.worldbank.org/5XL9LXK6B0. 
The Global Findex data set also includes novel cross-country data on self-reported reasons for not having a formal account, making it possible to identify barriers to financial inclusion. Moreover, the ability to disaggregate the data by individual characteristics allows researchers and policymakers to identify population groups that are excluded from the formal financial system and to better understand what characteristics are associated with certain financial behaviors.

Worldwide, by far the most common reason for not having a formal account, cited as the only reason by 30 percent of non-account holders, is lack of enough money to use one. This speaks to the fact that having a formal account is not costless in most parts of the world and that individuals with small or irregular income streams might view an account as an unnecessary expense, given the relatively high cost. Other reasons commonly reported for not having an account are that banks or accounts are too expensive (cited by 25 percent of adults without a formal account) and that the nearest banks are too far away (cited by 20 percent).

We examine the percentage of adults who saved, in the sense of deliberately putting aside money for future use, in the past year, and find that most saving in developing countries is done informally, even among adults who have a formal account. Worldwide, 36 percent of adults report having saved in the past year. Twenty-two percent of adults who reported saving (formally or informally) said they did so using a formal financial institution in the past 12 months. We also discuss informal saving and differences in the mode of saving across different income groups. In developing countries, for instance, 12 percent of account holders save using informal methods. The use of informal, community-based saving methods (such as rotating savings clubs) is also widespread, particularly in sub-Saharan African countries such as Cameroon, Kenya, and Nigeria.

We also find that most borrowing by adults in developing countries is from informal sources. Globally, 9 percent of adults report having originated a new loan from a formal financial institution in the past 12 months, while 23 percent report borrowing from family and friends. But in developing countries, adults are three times as likely to borrow from family and friends as from formal financial institutions ( 25 percent and 8 percent, respectively). In high-income countries, the most commonly cited purpose of an outstanding loan is to purchase a home; emergency and health reasons are those most frequently cited by adults in the developing world.

Finally, the Global Findex data set also provides new insight into the results of recent initiatives to expand financial inclusion. For instance, in Kenya 68 percent of adults in our sample report having used a mobile phone 
in the past 12 months to pay bills or to send or receive money; of these, almost two-thirds (41 percent of all adults) are otherwise unbanked. The spread of mobile money products, the increasing proliferation of bank agents, and the increasing movement toward dispensing government payments via formal accounts all offer potential to significantly alter the ways in which people manage their finances. Future rounds of data will allow us to document the pace of change in these behaviors.

The rest of the paper proceeds as follows. Section I defines and summarizes our financial inclusion indicators. Section II documents acrossand within-country variation in the use of formal and informal financial services. Section III discusses self-reported barriers to financial inclusion. Section IV discusses recent initiatives to expand financial inclusion, and section $\mathrm{V}$ concludes.

\section{Indicators and Methodology}

The Global Findex indicators measure the use of financial services, which is distinct from access to financial services. Access most often refers to the supply of services, whereas use is determined by demand as well as supply factors (World Bank 2008a). The Global Findex data can shed light on the levels and patterns of use of different financial services both globally and among different groups, such as poor people, youth, and women. But one cannot assume that all those who do not use formal financial services are somehow constrained from participating in the formal financial sectoraccess and use are not the same thing. The role of policy is to broaden financial inclusion to reach those who are excluded because of market failures.

\section{I.A. Indicators}

The first set of indicators focuses on the ownership and use of an account at a formal financial institution. For most people a formal account serves as an entry point into the formal financial sector. Having a formal account facilitates the transfer of wages, remittances, and government payments. It can also encourage formal saving and open access to credit. Accounts are also a simple and consistent metric that facilitates the measurement of financial inclusion across countries. Ownership and use of accounts are relatively easy to define and observe, and basic checking and savings accounts are fairly similar across countries.

The Global Findex survey includes several questions about accounts that investigate the mechanics of their use (frequency of use, mode of access), their purpose (receipt of payments from work, government, or family), 
barriers to their use, and alternatives to formal accounts (mobile money). Importantly, the survey's account penetration indicator measures the percentage of adults who have individual or joint ownership of a formal account, defined as an account at a formal financial institution such as a bank, credit union, cooperative, post office, or microfinance institution. It includes those who report having a debit or ATM card tied to an account.

The second set of indicators focuses on saving behavior. Savings allow individuals to smooth consumption, make large investments in education or to start a business, and mitigate uncertainty and risk. The concept of saving is inherently more subjective than those of account ownership and use. Individuals and cultures may have varying definitions of what constitutes saving. We focus on the purposeful action of saving, surveyed by asking individuals whether they have "saved or put aside any money" in the past year. We collect data on general saving behavior, as well as on the use of formal accounts and community-based methods to save. In doing so, we highlight the distinction between deliberate saving, whether formal or not, and the case where individuals simply consume less than their income. Individuals may save in the latter case as well (perhaps using informal means such as putting money under a mattress), but we are particularly interested in the use of formal accounts for saving.

The third set of indicators focuses on borrowing. Most people need to borrow money from time to time. They may want to buy or renovate a house, to invest in education, or to pay for a wedding or a funeral. When they lack enough money to do so, they turn to someone who will lend it to them: a bank, a cousin, or an informal lender. In some parts of the world many people rely on credit cards to obtain short-term credit. We gather data on the sources of borrowing (formal and informal), the purposes of borrowing (mortgage, emergency or health purposes, and the like), and the use of credit cards. ${ }^{5}$

5. In a few instances, surveyors and their supervisors reported that respondents were somewhat taken aback at the series of questions, given the personal nature of the topic. This concern was particularly relevant in countries with large security risks, such as Mexico and Zimbabwe, and in countries where personal finance is widely regarded as a private matter, such as Cameroon, Italy, and Portugal. There were also reports from the field that the terminology and concepts used in the survey were entirely new to some respondents. Although efforts were made to include simple definitions of such terms as "account" and "debit card," the unfamiliarity and complexity of the topic were still reported to be a hurdle in several countries, including Afghanistan, Cambodia, Chad, and rural Ukraine. Overall, however, the rate of "don't know" or "refuse" answers was very low. For the core questions (those not conditioned on the response to other questions), "don't know" or "refuse" responses made up fewer than 1 percent of the total and no more than 2 percent in any world region. 


\section{I.B. Data Coverage}

The Global Findex indicators are drawn from survey data collected over the 2011 calendar year, covering more than 150,000 adults in 148 countries that represent approximately 97 percent of the world's population. The survey was carried out by Gallup, Inc., in association with its annual Gallup World Poll. The Gallup World Poll has been used in previous academic studies, mostly to study well-being and social capital. For example, Angus Deaton (2008) uses Gallup World Poll questions on life and health satisfaction and looks at the relationships with national income, age, and life expectancy. Gallup World Poll questions are also used by Betsey Stevenson and Justin Wolfers (2008) and by Daniel Sacks, Stevenson, and Wolfers (2010) as part of their research to analyze relationships between subjective well-being and income; by Bianca Clausen, Aart Kraay, and Zsolt Nyiri (2011) to analyze the relationship between corruption and confidence in public institutions; by Demirgüç-Kunt and others (2013) to study changes in trust in banks in the wake of the global financial crisis; and by Stevenson and Wolfers (2011) to examine trust in institutions over the business cycle.

As part of the World Poll, since 2005 Gallup has surveyed about 1,000 people annually in each of up to 157 countries, ${ }^{6}$ using randomly selected, nationally representative samples. ${ }^{7}$ The target population is the entire civilian, noninstitutionalized population aged 15 and above. Surveys are conducted in the major languages of each country. ${ }^{8}$

Although the results obtained using the Global Findex data are broadly consistent with those of earlier efforts, they differ in some nontrivial ways. Three key differences between the Global Findex and other user-side data involve the definition of an account and its use, the units of measurement

6. The worldwide aggregates omit countries for which Gallup excludes more than 20 percent of the population in the sampling either because of security risks or because the population includes non-Arab expatriates. These excluded countries are Algeria, Bahrain, the Central African Republic, Madagascar, Qatar, Somalia, and the United Arab Emirates. Iran is also excluded because the data were collected in that country using a methodology inconsistent with that used for other countries (the survey was carried out by phone from Turkey). The exclusion of Iran has a nontrivial effect on regional aggregates because its population is larger and wealthier than the populations of most other countries in the Middle East and North Africa. For example, account penetration in the region is estimated to be 18 percent when Iran is excluded, but 33 percent when it is included.

7. In some countries oversamples are collected in major cities or areas of special interest. In addition, in some large countries, such as China and Russia, sample sizes of at least 4,000 are collected.

8. For details on the data collection dates, sample sizes, excluded populations, and margins of error, see www.worldbank.org/globalfindex. 
such as age cutoffs, and when the data were collected. Relative to other demand-side data efforts, one significant advantage of the Global Findex data is that they are consistent and comparable across countries. Two commonly cited cross-country user-side data collection efforts are the FinMark Trust's FinScope initiative, a specialized household survey in 14 African countries and Pakistan, and the European Bank for Reconstruction and Development's Life in Transition Survey (LITS), which covers 35 countries in Central and Eastern Europe and Central Asia and includes several questions on financial decisions as part of a broader survey. The Global Findex country-level estimates of account penetration are generally insignificantly different from or higher than those of the FinScope surveys, perhaps because of the difference in timing (most of the FinScope surveys were carried out in the mid-2000s) and in the definition of an account (Global Findex includes only accounts that can be used for both deposits and withdrawals). The Global Findex estimates of account penetration are within 7 percentage points of the LITS estimates for the majority of countries; the discrepancies are perhaps explained by the fact that the LITS financial access question is less descriptive than the corresponding questions in the Global Findex survey. ${ }^{9}$ Compared with data collected from the providers of financial services (financial institutions), the Global Findex data may fill a gap by going beyond data collected only from regulated financial institutions and allowing disaggregation of the data by demographic characteristics. ${ }^{10}$

\section{I.C. Survey Methodology}

The survey methodology for the Global Findex data is that used for the Gallup World Poll. Surveys are conducted by telephone except in countries where telephone coverage represents less than 80 percent of the popula-

9. The exact question in the LITS survey is "Does anyone in your household have a bank account?"

10. On the provider side, the International Monetary Fund collects indicators of financial outreach such as the number of bank branches and automated teller machines (ATMs) per capita and per square kilometer, as well as the number of loan and deposit accounts per capita, directly from country regulators. These data sets are important sources of basic cross-country indicators developed at a relatively low cost. Yet indicators based on data collected from financial service providers have several important limitations. First, data are collected from regulated financial institutions only and thus provide a fragmented view of financial access. Second, aggregation can be misleading because of multiple accounts or dormant accounts (see Beck, Demirgüç-Kunt, and Martinez Peria 2008 for a discussion). Most important, this approach does not allow disaggregation of financial service users by income or other characteristics. That leaves policymakers unable to identify those segments of the population with the lowest use of financial services, such as the poor, women, or youth. 
tion; in these countries the survey is conducted face to face. ${ }^{11}$ In most countries the fieldwork is completed in 2 to 4 weeks. In countries where Gallup has conducted face-to-face surveys, the identification of primary sampling units, consisting of clusters of households, constitutes the first stage of sampling. The primary sampling units are stratified by population size, geography, or both, and clustering is achieved through one or more stages of sampling. Where population information is available, sample selection is based on probabilities proportional to population size; where otherwise, simple random sampling is used. Random route procedures are used to select sampled households. Unless an outright refusal occurs, interviewers make up to three attempts to survey the sampled household. If an interview cannot be obtained at the initial sampled household, a simple substitution method is used. Respondents are randomly selected within the selected households by means of the Kish grid. ${ }^{12}$

In countries where telephone interviewing is employed, random-digit dialing or a nationally representative list of phone numbers is used. In selected countries where cell phone penetration is high, a dual sampling frame is used. Random respondent selection is achieved by using either the latest-birthday method or the Kish grid method. ${ }^{13}$ At least three attempts are made to reach a person in each household, spread over different days and times of day.

\section{I.D. Data Weighting}

Data weighting is used to ensure a nationally representative sample for each country. First, base sampling weights are constructed to account for oversamples and household size. If an oversample has been conducted, the data are weighted to correct the disproportionate sample. Weighting by

11. Croatia, the Czech Republic, Estonia, Greece, Hungary, Poland, Singapore, and the Slovak Republic are the only high-income countries included where phone coverage is less than 80 percent.

12. The Kish grid is a table of numbers used to select the interviewee in each household. First, the interviewer records the name, sex, and age of all permanent household members aged 15 and above, whether or not they are present, and then numbers them starting with the oldest and ending with the youngest. Second, the interviewer finds the column number of the Kish grid that corresponds to the last digit of the questionnaire number, and the row number for the number of eligible household members. The number in the cell where column and row intersect determines the person selected for the interview. In countries where cultural restrictions dictate matching interviewer and interviewee by sex, respondents are randomly selected using the Kish grid from among all eligible adults of the interviewer's sex.

13. In the latest-birthday method an interview is attempted with the adult in the household who had the most recent birthday. 
household size (number of residents aged 15 and above) is used to adjust for the probability of selection, as residents in large households will have a disproportionately lower probability of being selected for the sample. Second, poststratification weights are constructed. Population statistics are used to weight the data by sex, age, and (where reliable data are available) education or socioeconomic status. Finally, approximate study design effects and margins of error are calculated. The average country-level margin of error for the account penetration indicator is \pm 3.9 percent. All income group aggregates are also weighted by country population (aged 15 and above).

\section{Individual- and Country-Level Variation in Financial Inclusion}

In this section we discuss the main findings from our analysis of the Global Findex database to highlight broad patterns in financial inclusion across the globe. We focus on several indicators that we believe are particularly important for understanding the financial behavior of adults, including the ownership and use of formal accounts, the prevalence of formal and informal saving behavior, and the sources and purposes of borrowing. We first examine country-level variation in account penetration across countries and regions. Next, we focus on differences in the use of financial products across individuals, and how disparities by individual characteristics vary across countries. We also identify trends in account ownership such as frequency and mode of use. We then discuss saving behavior. In particular, we identify trends in the use of formal and informal methods of saving across countries and across income groups within countries. Finally, we highlight patterns in access to and sources of credit worldwide.

The variation in the data-pertaining to accounts, saving, and credithighlights differences in countries' levels of financial inclusion. It also emphasizes that the nature of the use of financial services, such as frequency of account use or purpose of obtaining credit, not only varies across countries but may be widely divergent within any given country as well. By focusing on both within- and cross-country inequality, we identify patterns in the data that may be useful to governments in informing their financial inclusion strategies, and to private sector actors in new product development.

\section{II.A. Accounts and Payments}

EXPLAINING VARIATION IN ACCOUNT PENETRATION Account penetration differs enormously between high-income and developing countries in the aggregate: 89 percent of adults in high-income countries, but only 24 percent in 
Figure 1. Formal Account Penetration, by Country Income Group

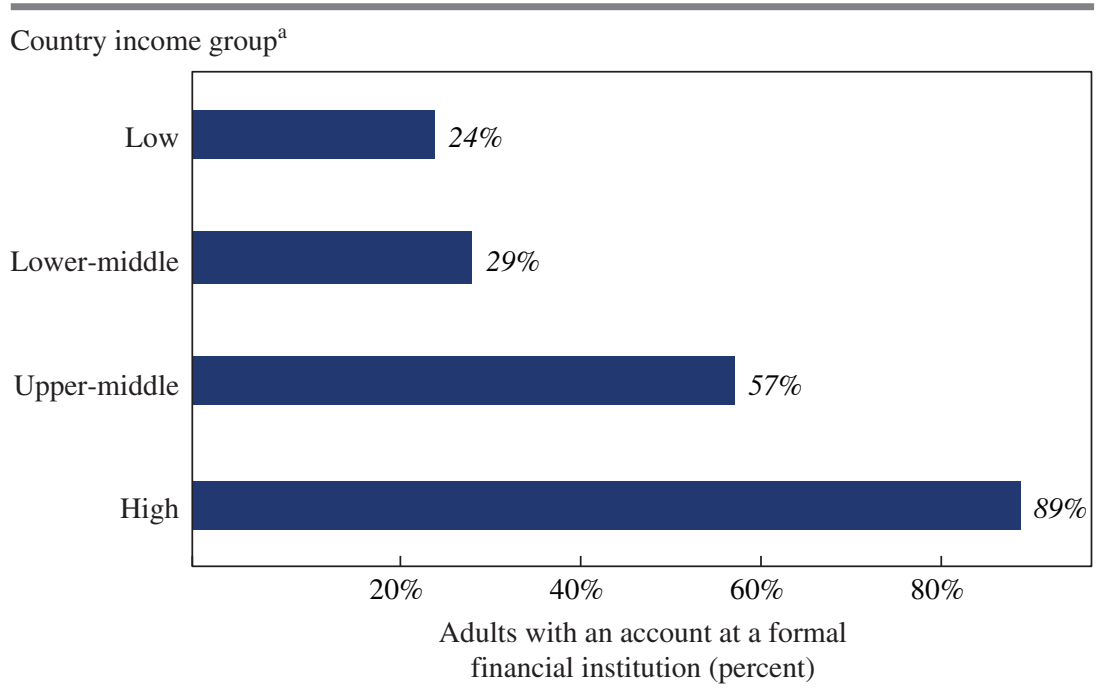

Source: Authors' calculations using Global Findex data.

a. Low-income countries are those with gross national income per capita less than $\$ 1,025$ in 2011 ; lower-middle-income countries, \$1,026-\$4,035; upper-middle-income countries, $\$ 4,036-\$ 12,475$; highincome countries, $\$ 12,476$ or more.

low-income countries, report that they have an account at a formal financial institution (figure 1). Globally, 50 percent of the world's population-more than 2.5 billion adults— do not have a formal account (figure 2). The majority of these reside in developing countries. ${ }^{14}$ In several countries around the world - including Cambodia, the Democratic Republic of Congo, Guinea, the Kyrgyz Republic, Turkmenistan, and Yemen-more than 95 percent of adults lack a formal account. Appendix B reports the percentage of adults with a formal account in each country surveyed.

Why is account penetration high in, say, Denmark but almost negligible in Niger? GDP per capita accounts for much of the variation across countries (top panel of figure 3): Denmark is among the world's richest countries whereas Niger is among the poorest. In most countries with a GDP per capita of $\$ 15,000$ or higher, account penetration is 90 percent or higher. ${ }^{15}$ Indeed, regression analysis shows that national income per capita

14. According to the latest available data from the World Bank's World Development Indicators, there are 5.08 billion adults aged 15 and above worldwide.

15. Exceptions include Italy (with an account penetration of 71 percent) and the United States (88 percent). 
Figure 2. Formal Account Penetration Worldwide

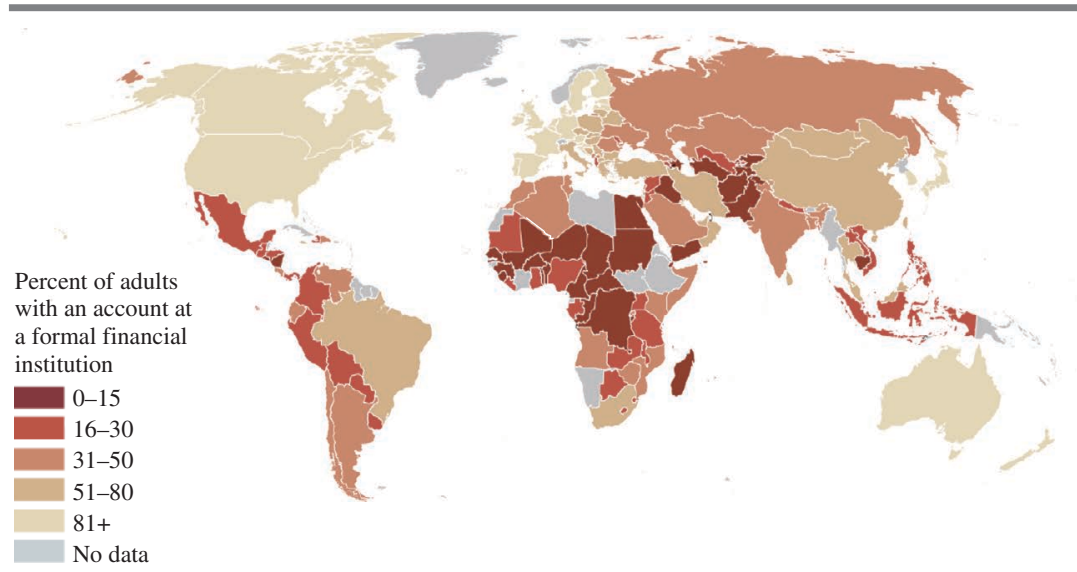

Source: Authors' calculations using Global Findex data.

is significantly associated with account penetration and accounts for about 70 percent of the variation among the world's countries in the share of adults with a formal account (column 1-1 in table 1). Country-level regressions also show that whereas adults in low-income countries are 72 percent less likely to have an account than adults in high-income countries, adults in upper-middle-income countries are only 43 percent less likely (column 1-2). We find significant difference in account penetration between adults in lowincome countries and in lower-middle-income countries and a significant gap between adults in lower-middle-income and in upper-middle-income countries (column 1-2, bottom rows).

National-level financial development, as measured by domestic credit to the private sector as a percentage of GDP, is also significantly associated with account penetration (bottom panel of figure 3), even when one controls for GDP per capita (column 1-3 in table 1). However, large amounts of credit-whether commercial or consumer credit-in a financial system do not always correspond to broad use of financial services, because credit can be concentrated among the largest firms and the wealthiest individuals. For instance, domestic credit to the private sector amounts to 112 percent of GDP in Vietnam, but only 21 percent of adults in that country report having a formal account. Conversely, in the Czech Republic, a country with relatively modest financial depth (domestic credit to the private sector is 55 percent of GDP), account penetration is relatively high (81 percent). 
Figure 3. Formal Account Penetration, GDP per Capita, and Financial Development ${ }^{\mathrm{a}}$

Account penetration and GDP per capita

Percent of adults with

a formal account

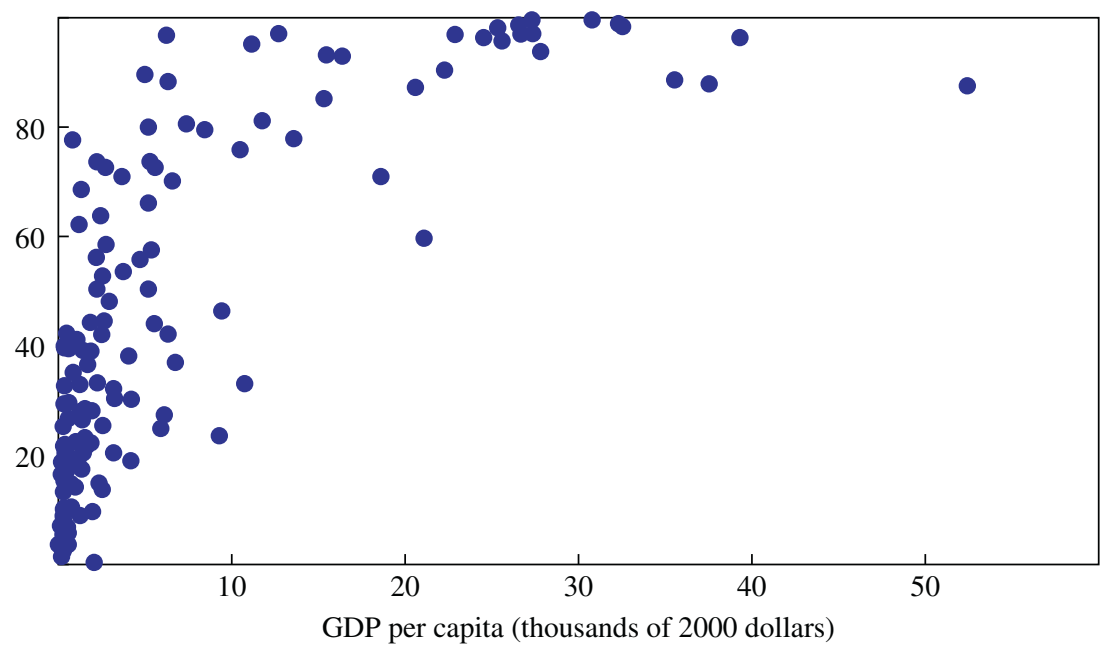

Account penetration and financial development

Percent of adults with

a formal account

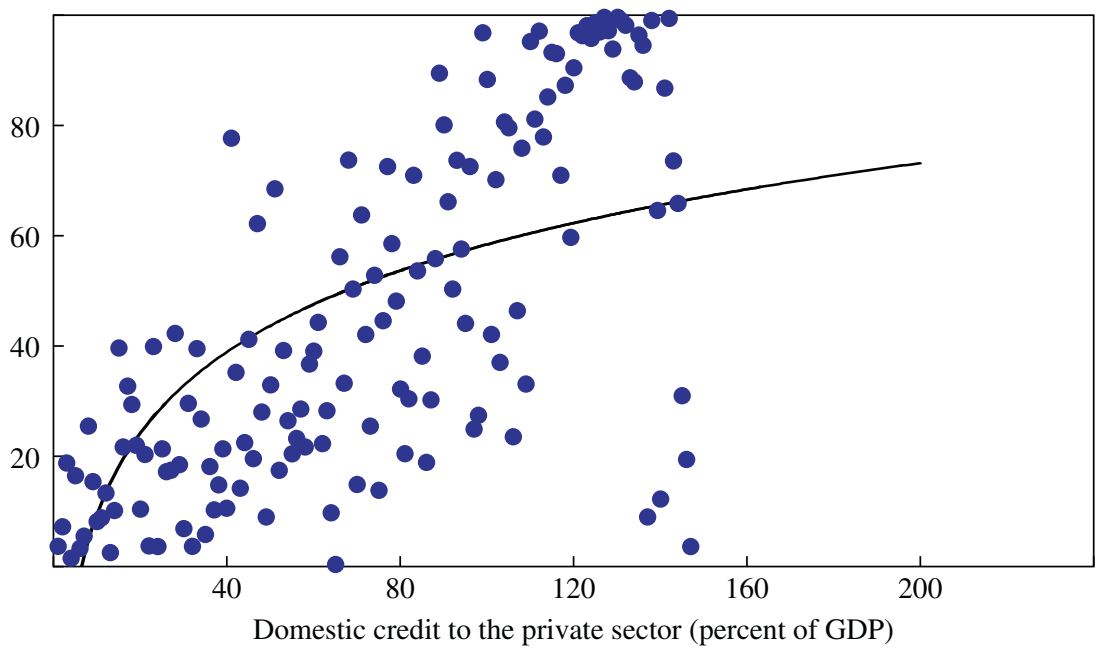

Source: Authors' calculations using Global Findex and World Development Indicators data.

a. Each observation represents 1 of 140 (top panel) or 130 (bottom panel) developing and high-income countries. 
Table 1. Country-Level Regressions Explaining Financial Inclusion ${ }^{\mathrm{a}}$

\begin{tabular}{|c|c|c|c|c|c|c|}
\hline \multirow{3}{*}{$\begin{array}{l}\text { Independent } \\
\text { variable }\end{array}$} & \multicolumn{6}{|c|}{ Dependent variable } \\
\hline & \multicolumn{4}{|c|}{$\begin{array}{l}\text { Percent of adults reporting having an account at a } \\
\text { formal financial institution }\end{array}$} & \multirow{2}{*}{$\begin{array}{l}\text { Percent } \\
\text { reporting } \\
\text { formal } \\
\text { saving }^{\mathrm{b}} \\
1-5\end{array}$} & \multirow{2}{*}{$\begin{array}{l}\text { Percent } \\
\text { reporting } \\
\text { use of } \\
\text { formal } \\
\text { credit }^{\mathrm{c}} \\
1-6\end{array}$} \\
\hline & $1-1$ & $1-2$ & $1-3$ & $1-4$ & & \\
\hline $\begin{array}{l}\text { Logarithm of } \\
\text { GDP per } \\
\text { capita }^{\mathrm{d}}\end{array}$ & $\begin{array}{l}0.105 * * * \\
(0.014)\end{array}$ & & $\begin{array}{l}0.122 * * * \\
(0.014)\end{array}$ & $\begin{array}{l}0.157 * * * \\
(0.012)\end{array}$ & & \\
\hline $\begin{array}{l}\text { Low-income } \\
\text { country }(1)^{\mathrm{e}}\end{array}$ & & $\begin{array}{l}-0.436 * * * \\
(0.106)\end{array}$ & & & $\begin{array}{l}-0.316 * * * \\
(0.027)\end{array}$ & $\begin{array}{l}-0.063^{* * * *} \\
(0.014)\end{array}$ \\
\hline $\begin{array}{l}\text { Lower-middle- } \\
\text { income } \\
\text { country }(2)^{\mathrm{e}}\end{array}$ & & $\begin{array}{l}-0.442 * * * \\
(0.079)\end{array}$ & & & $\begin{array}{l}-0.313 * * * \\
(0.025)\end{array}$ & $\begin{array}{l}-0.052 * * * \\
(0.013)\end{array}$ \\
\hline $\begin{array}{l}\text { Upper-middle- } \\
\text { income } \\
\text { country }(3)^{\mathrm{e}}\end{array}$ & & $\begin{array}{l}-0.325 * * * \\
(0.053)\end{array}$ & & & $\begin{array}{l}-0.276 * * * \\
(0.024)\end{array}$ & $\begin{array}{l}-0.039 * * * \\
(0.013)\end{array}$ \\
\hline $\begin{array}{l}\text { Domestic } \\
\text { credit to the } \\
\text { private sec- } \\
\text { tor (percent } \\
\text { of GDP) }\end{array}$ & & & $\begin{array}{l}0.185 * * * \\
(0.037)\end{array}$ & & & \\
\hline Gini index ${ }^{d}$ & & & & $\begin{array}{l}-0.488 * * \\
(0.190)\end{array}$ & & \\
\hline Constant & & $\begin{array}{c}0.203 \\
(0.241)\end{array}$ & $\begin{array}{l}-0.606 * * * \\
(0.093)\end{array}$ & $\begin{array}{l}-0.582 * * * \\
(0.126)\end{array}$ & $\begin{array}{l}0.407 * * * \\
(0.017)\end{array}$ & $\begin{array}{l}0.135 * * * \\
(0.009)\end{array}$ \\
\hline $\begin{array}{l}\text { No. of } \\
\text { observations } \\
\text { (countries) }\end{array}$ & 134 & 134 & 123 & 110 & 139 & 139 \\
\hline$R^{2}$ & 0.772 & 0.783 & 0.747 & 0.662 & 0.622 & 0.160 \\
\hline $\begin{array}{l}p \text { value of } \\
F \text { statistic }\end{array}$ & & & & & & \\
\hline$H_{0}:(1)=(2)$ & & 0.904 & & & 0.931 & 0.443 \\
\hline$H_{0}:(2)=(3)$ & & 0.015 & & & 0.127 & 0.310 \\
\hline
\end{tabular}

Source: Authors' regressions using Global Findex and World Development Indicators data.

a. Each column reports results of a single ordinary least squares regression. Standard errors are in parentheses. Asterisks denote significance at the ***1 percent, **5 percent, and $* 10$ percent level.

b. Percent of adults reporting having saved or put aside money at a formal financial institution in the past 12 months.

c. Percent of adults reporting having borrowed from a formal financial institution in the past 12 months.

d. Data are for 2011 or the most recent year available.

e. Dummy variable equal to 1 when the country is a member of the indicated country income group, and zero otherwise. High-income countries are the omitted category. 
Figure 4. Formal Account Penetration, by Country Income Group and Within-Country Income Quintile

Percent of adults with

a formal account

Top quintile

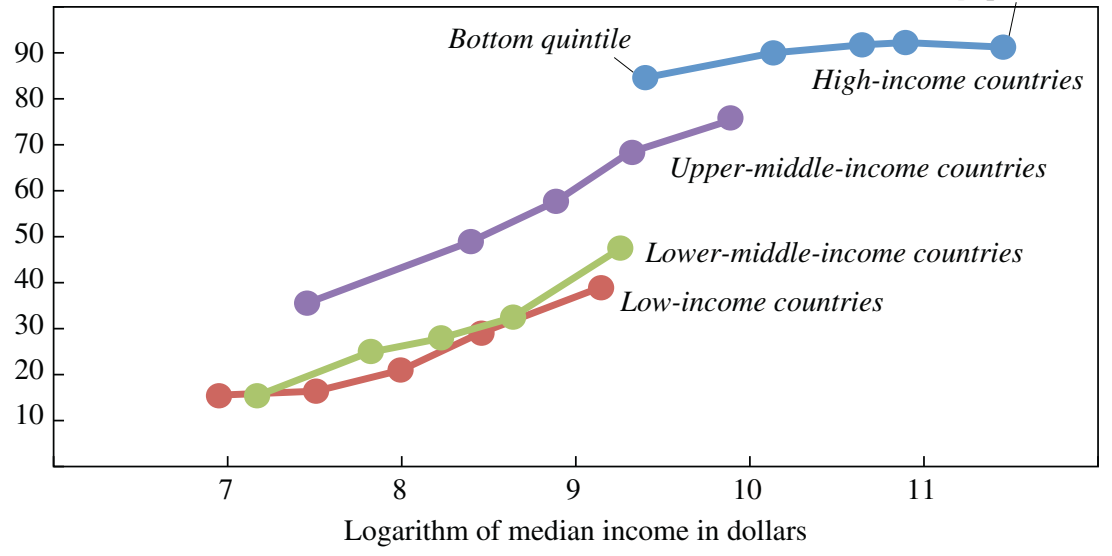

Source: Authors' calculations using Global Findex data.

These findings suggest that financial depth and financial inclusion are related but ultimately distinct dimensions of financial development, and that financial systems can become deep without delivering access for all. A more formal investigation of the country-level determinants of financial inclusion is beyond the scope of this paper, but the theme is explored further using Global Findex data by Franklin Allen and others (2012).

ACCOUNT PENETRATION ACROSS INDIVIDUAL CHARACTERISTICS BeyOnd crosscountry variation, there is also significant variation in account penetration across individuals within a given country. Examining account penetration by within-country income quintile highlights differences between the poor and the better off. The differences in slope from one segment to the next in each of the lines in figure 4 indicate the differences in account penetration between income quintiles for the country income group represented by that line-a rough measure of the gap in financial inclusion between richer and poorer individuals at a given level of country income per capita. Because the upper limit is 100 percent, there is little absolute difference in the slopes between the dots for the high-income countries as a group. In these countries, on average, poorer adults are not significantly less likely than richer adults to have a formal account. But stark differences exist in account penetration within most developing countries. In the upper-middle- 
income countries the slope of the line is very steep, but relatively constant across segments. The richest adults in these countries are more than twice as likely as the poorest to have a formal account, with a gap of approximately 10 percentage points separating each pair of quintiles. The lower-middleincome countries exhibit sharp differences between the poorest and the middle class, as well as between the middle class and the rich, highlighted by the kinks in the curve. In the low-income countries, account ownership does not vary significantly across the bottom two income quintiles, but it increases steadily as income increases further.

Two other results in figure 4 are striking. First, account penetration in the poorest quintile in the high-income countries is 9 percentage points higher on average than in the richest quintile in the upper-middle-income countries. Second, account penetration in the richest quintile in the low-income countries is only 4 percentage points higher than in the poorest quintile in the upper-middle-income countries.

We also estimate multivariate probit models using individual-level data to test the relationship between account ownership and income quintile, controlling for other individual characteristics such as sex, age, education, marital status, household size, employment, and rural versus urban residence. The leftmost panel of table 2 reports marginal effects for the bottom four income quintiles (the richest income quintile is the excluded category), which show significant differences in within-country "financial inequality" across country income groups. Although in all country income groups, adults in the highest income quintile are significantly more likely to be banked, in the high-income countries that difference is small: the poorest 20 percent are only 5 percent less likely to have an account than the richest 20 percent, whereas in the upper-middle-income countries the poorest 20 percent of earners are 24 percent less likely, and in low-income countries the poorest earners are 13 percent less likely.

These findings may be explained in part by differences in economic inequality across country income groups. Indeed, we find a strong correlation across countries (a correlation coefficient of 0.42) between inequality in the use of formal accounts and income inequality as measured by the Gini coefficient (with higher values indicating a more unequal income distribution). The correlation between these two measures of financial and economic inequality continues to hold even when we control for national income per capita (column 1-4 of table 1).

Consider the example of the United Kingdom and the United States. These two countries have relatively similar GDP per capita and relatively similar account penetration among adults in the top four income quintiles 


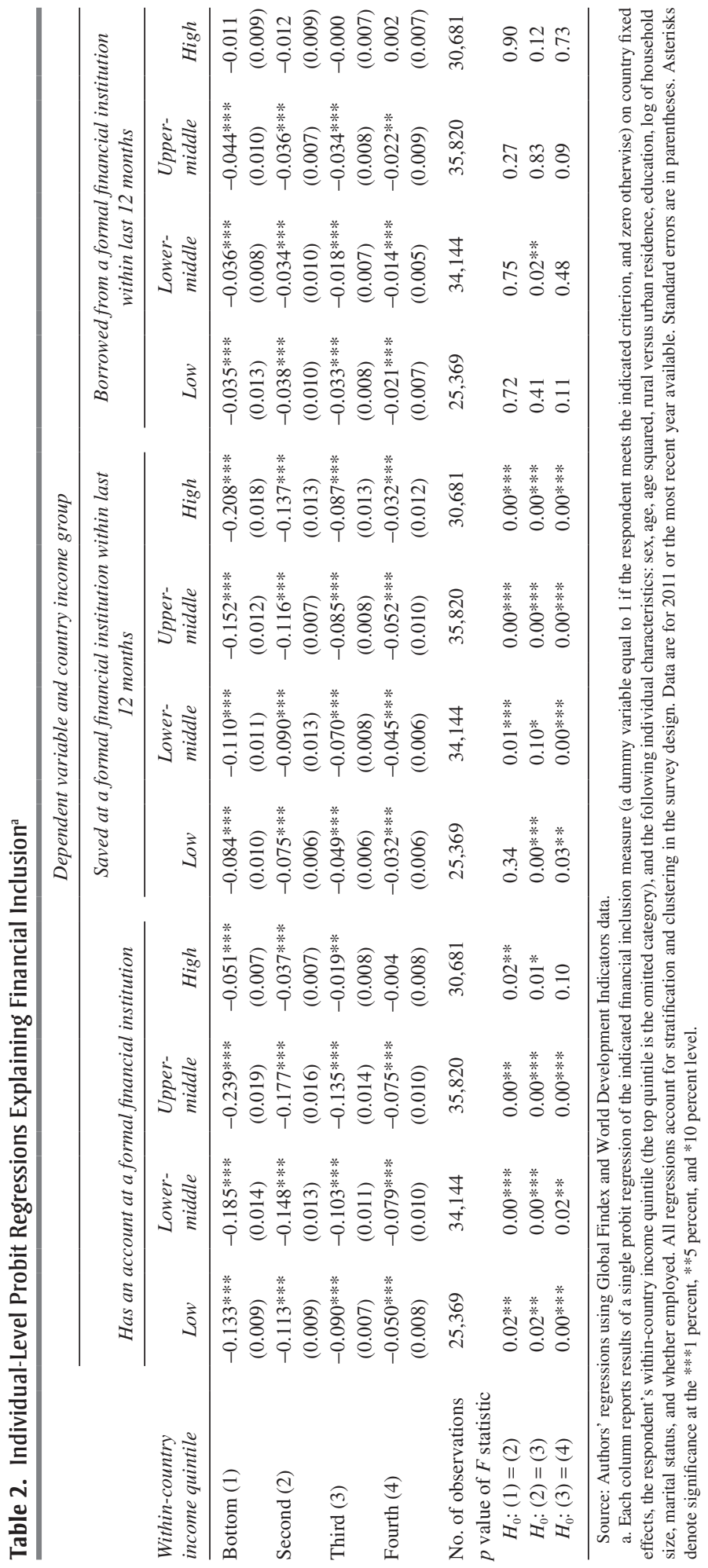


Figure 5. Formal Account Penetration in the Poorest Quintile, Selected High-Income Countries

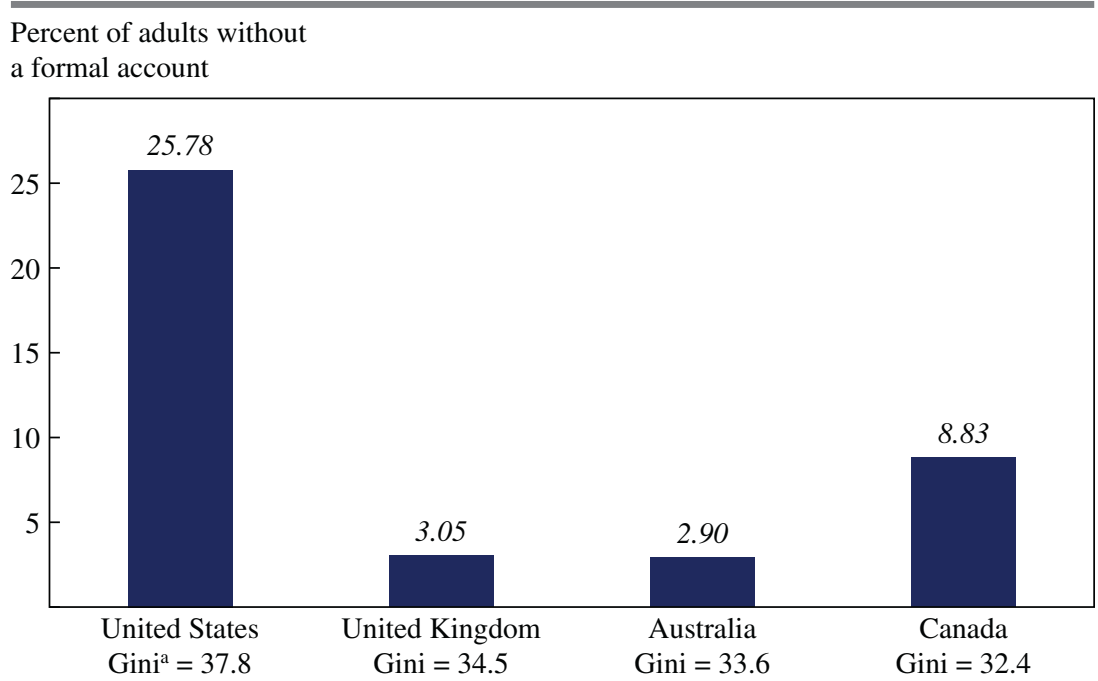

Source: Authors' calculations using Global Findex and Organization for Economic Cooperation and Development (OECD) data.

a. A higher Gini index indicates greater income inequality.

(98 percent and 92 percent, respectively). But the Gini coefficient in the United Kingdom is smaller than that in the United States, which may help explain the sharp difference between the two countries in account penetration in the poorest income quintile (figure 5). In the United States 26 percent of adults in this group report having no formal account; the corresponding number for the United Kingdom is 3 percent. Such differences serve to reinforce the hypothesis that although the correlation between income per capita or income inequality and account penetration explains some variation in the use of financial services, it by no means explains all of it. Alternative explanations included differences in trust in banks and the availability of alternatives to formal financial institutions. (A 2011 survey by the Federal Deposit Insurance Corporation also found a large gap in account penetration between rich and poor households within the United States.) Bottom-quintile adults in the United States are also much less likely to have an account than their counterparts in Australia or Canada-two other countries with broadly similar economic development and legal traditions to those of the United States, but with smaller Gini coefficients.

CROSS-COUNTRY DIFFERENCES IN THE USE OF ACCOUNTS Beyond the simple ownership of formal accounts, data on the frequency and methods of use of 
those accounts shed light on some stark differences between high-income and developing countries. In developing countries, 10 percent of account holders-more than 150 million people worldwide-maintain what can be considered an inactive account: they make neither withdrawals from nor deposits into their account in a typical month (although they may maintain a positive balance). In contrast, only 2 percent of account holders in highincome countries have an inactive account.

The majority of adults with a formal account in developing countries make deposits or withdrawals only once or twice in a typical month. In high-income countries, by contrast, more than half of account holders withdraw money from their accounts six or more times in a typical month. ATMs and electronic payment systems (debit cards, electronic bill payments, and the like) facilitate access to accounts. Indeed, adults with a formal account in high-income countries report most commonly using ATMs for withdrawals. Those in developing countries report most commonly making withdrawals over the counter, in a branch of their bank or at another financial institution.

People also have myriad reasons for maintaining an account at a formal financial institution. Using a formal account to receive wages is most common in high-income countries, where 50 percent of adults report using an account for this purpose, compared with 14 percent of adults in developing countries. Relying on an account to receive payments from the government is also most common in high-income countries, where 42 percent of all adults (and 47 percent of account holders) report having used their account for this type of transaction in the past year, compared with 6 percent of adults in developing countries. Accounts are also used to send money to or receive money from relatives by 8 percent of all adults (and 21 percent of account holders) in developing countries.

\section{II.B. Saving}

Saving to cover future expenses — education, a wedding, a big purchaseor to provide against possible emergencies is a universal practice. However, not only does the propensity to save differ across and within countries; the mode and the purpose of saving also vary. Globally, 36 percent of adults report having saved (in the sense of deliberately setting aside money) in the past year, although this ranges from 30 percent in low-income countries to 58 percent in high-income countries.

More interesting are the marked differences in how people save. A proportion of adults who save do so using a formal account. But many others, including some who own a formal account, turn to alternative methods of 
Figure 6. Participation in Formal Saving, by Country Income Group and Within-Country Income Quintile

Percent of adults with

a formal account

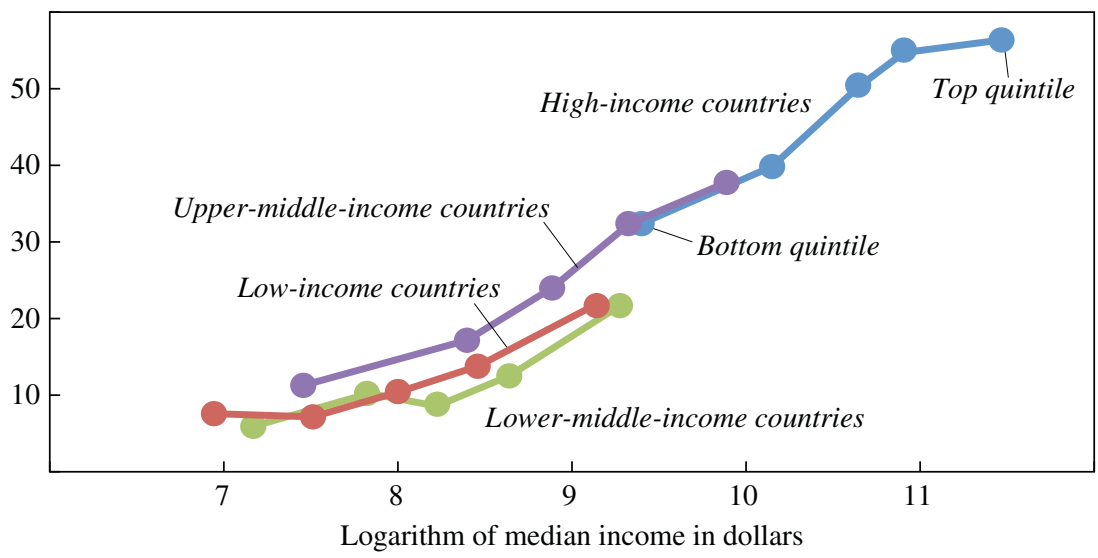

Source: Authors' calculations using Global Findex data.

saving. Worldwide, about one-fourth of adults report having saved at a bank, credit union, or microfinance institution in the past year. This figure ranges from 45 percent in high-income countries, to 24 percent in uppermiddle-income countries, to 11 percent in lower-middle-income and lowincome countries. The difference between high- and upper-middle-income countries in the percentages of adults who saved formally is statistically significant, but there is no statistically significant difference among developing-country income groups (column 1-5 in table 1).

Like account penetration, formal saving behavior also varies with individual characteristics within countries. As figure 6 shows, in high-income countries as a group, the share of adults who engage in formal saving rises sharply with income in the bottom half of the income distribution, from 32 percent in the bottom quintile to 50 percent in the middle quintile, but becomes much flatter in the top half, rising only from 50 percent to 56 percent. This suggests that in high-income countries, individuals in the middle class are significantly more likely to save formally than the poor, and only marginally less likely to save formally than the rich.

The share of adults who save increases more linearly in upper-middleincome countries: a gap of about 6 percentage points is seen between each income quintile. Finally, in lower-middle- and low-income countries 
there is almost no difference between the middle class and the poor in the proportion of adults saving formally: for the lower-middle-income countries the numbers are roughly 9 percent and 6 percent, respectively. However, in both these groups of countries the rich are more than twice as likely to save formally as the middle class: about 21 percent compared with about 9 percent in the case of the lower-middle-income countries. Probit estimations using individual-level data confirm these results. For instance, in high-income countries adults in the poorest income quintile are 21 percent less likely to save formally than adults in the richest quintile, whereas in low-income countries the difference is only 8 percent (compare the first and the last columns of the middle panel of table 2).

Saving behavior varies among account holders as well: even individuals who have a formal account may not necessarily use it to save. Worldwide, about 43 percent of account holders report having set aside money at a formal financial institution in the past year; the figure varies relatively little across country income groups. However, in many sub-Saharan African countries, such as Liberia and Uganda, more than 65 percent of account holders report saving formally. This suggests that in these countries the ability to save in a secure location may motivate individuals to open and maintain a formal account. In contrast, in many countries in Central and Eastern Europe and Central Asia, adults do not primarily use their accounts to save: in this region fewer than one in six adults with a formal account report having saved or set aside money using a formal account in the past year. In Georgia just 3 percent of account holders (and 1 percent of all adults) report having saved using a formal account in the past year. However, adults in this region are especially likely to use their accounts to receive wages and government payments. This ability, rather than the opportunity for saving, may thus be a key reason why these adults own formal accounts.

Many adults, despite having a formal account, save solely using other methods. These people, who might be classified as the "underbanked," constitute 12 percent of account holders worldwide. Individuals may choose an informal saving method rather than use their formal account because the costs of using their account are prohibitively high. Barriers such as minimum balance and withdrawal fees and physical distance often raise the cost of opening and maintaining a formal account. It is also possible that accounts set up by an employer or the government are not conducive to saving. If that is the case, policymakers or commercial banks in countries where greater financial inclusion is a priority could introduce new products to encourage existing account holders to save in formal 
institutions. Such products could be especially important in countries with aging populations. ${ }^{16}$

In developing countries, savings clubs often serve as an alternative (or complement) to saving at a formal financial institution. One common form of such clubs is the rotating savings and credit association (ROSCA), known locally as a susu in West Africa, an arisan in Indonesia, and a pandero in Peru. These clubs generally operate by pooling the weekly deposits of their members and disbursing the entire amount to a different member each week. Although members generally do not earn interest on their deposits as in a formal account, these clubs can provide members an opportunity to save.

Savings clubs and other community-based saving methods are widely used in some parts of the world, particularly in low-income countries. In sub-Saharan Africa 19 percent of adults report having saved in the past year using a savings club or a person outside the family. Among just those who report any saving activity in the past 12 months, 48 percent used community-based methods. The practice is particularly common in Nigeria, where ROSCAs are called esusu, ajo, cha, or adashi. In Nigeria 44 percent of adults (and 69 percent of those who save) report using a savings club or a person outside the family. Perhaps because of the widespread use of this saving method, the share of Nigerians who report any type of saving in the past year is equal to that in Canada and South Korea and far higher than that in most other developing countries.

The popularity of savings clubs speaks to their advantages, but these arrangements also have their downside. Their defining characteristic, informality, is accompanied by risks of fraud and collapse. Of course, formal accounts are not immune to these risks, especially in many developing countries where explicit government-run deposit insurance is absent or inadequate. In addition, the cyclical nature of contributions and disbursements in a ROSCA may be too rigid for some people. A fixed schedule may not serve their need to deposit surplus income when available or to quickly withdraw funds in an emergency.

Community-based saving methods and formal financial institutions are not the only options for saving. A large share of adults around the world who report having set aside money in the past year used neither a formal financial institution, nor an informal savings club, nor a person outside the family. Although the Global Findex survey did not gather data on other

16. See, for example, Chawla, Betcherman, and Banerji (2007), who provide an overview of the challenges of aging populations in Eastern Europe and the former Soviet Union. 
alternative methods, they might include saving through asset accumulation (such as gold or livestock) and saving "under the mattress." ${ }^{17}$ These adults account for 29 percent of savers worldwide and more than half of savers in 55 countries.

\section{II.C. Borrowing}

In the Global Findex data, the overall rate of origination of new loans, formal and informal, is fairly steady across country income groups and individual characteristics. On average, almost one-third of adults in both high-income and developing countries report having borrowed money in the past year. However, measures of new (or rolled-over) household debt are sensitive to the business cycle and other current economic factors, and future rounds of data collection may yield significantly different estimates. Moreover, the use of credit is sensitive to the tax, legal, and regulatory environment of the country in question. For example, the provision of private credit is higher in countries with better creditor protection and broader credit information coverage (Djankov, McLiesh, and Shleifer 2007).

Beyond the overall rate of new borrowing, however, high-income and developing countries exhibit little commonality in the sources and purpose of credit. Individuals in higher-income countries are significantly more likely to borrow from formal sources, such as banks or retail stores (column 1-6 of table 1; see also figure 7). Those in lower-income countries are more likely to use informal sources of credit such as family and friends. To illustrate, in Finland 24 percent of adults report having borrowed from a formal financial institution in the past year; in Ukraine only 8 percent report having done so, and in Burundi only 2 percent. The pattern is reversed with respect to the proportion of adults with informal credit: 37 percent of adults in Ukraine and 44 percent in Burundi, but only 15 percent in Finland, report having borrowed from family or friends in the past 12 months.

This propensity toward informal rather than formal lending is observed in both low- and middle-income countries. Friends and family are the most commonly reported source of new loans in upper-middle-, lower-middle-, and low-income countries, but not in high-income countries (figure 8). In low-income countries 20 percent of adults report friends or family as their only source of new loans in the past year; only 6 percent report a formal financial institution as their only source. Adults in poorer countries are also

17. Because of the sensitivity of household finances and the inhibitions brought about by face-to-face surveys, the Global Findex survey did not probe deeply into the practices of "under the mattress" saving in the home. 
Figure 7. Origination of New Formal Loans Worldwide

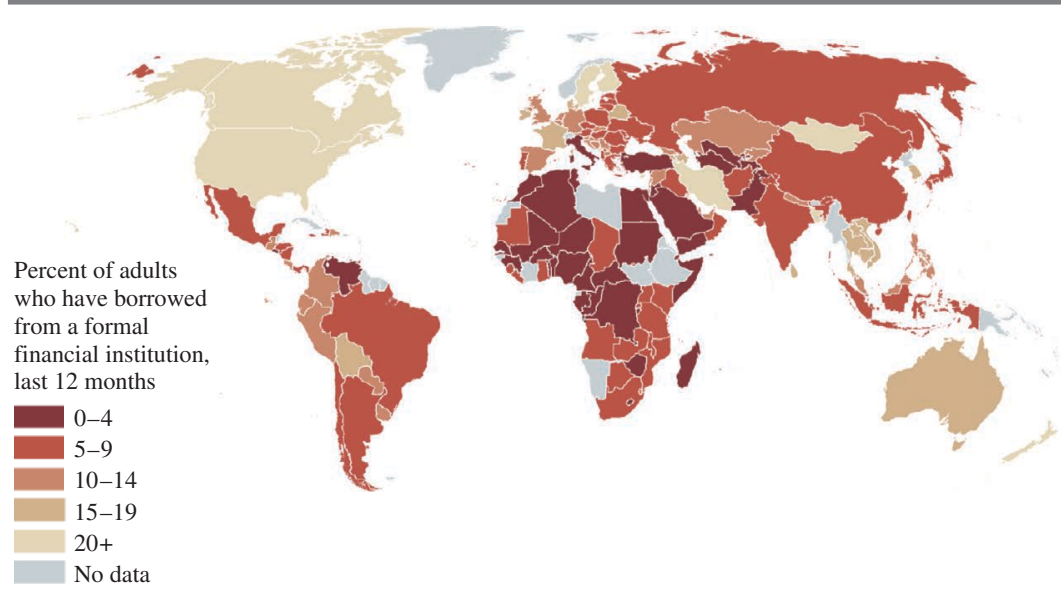

Source: Authors' calculations using Global Findex data.

Figure 8. Sources of New Loans, by Country Income Group

Percent of adults using

the indicated source ${ }^{\mathrm{a}}$

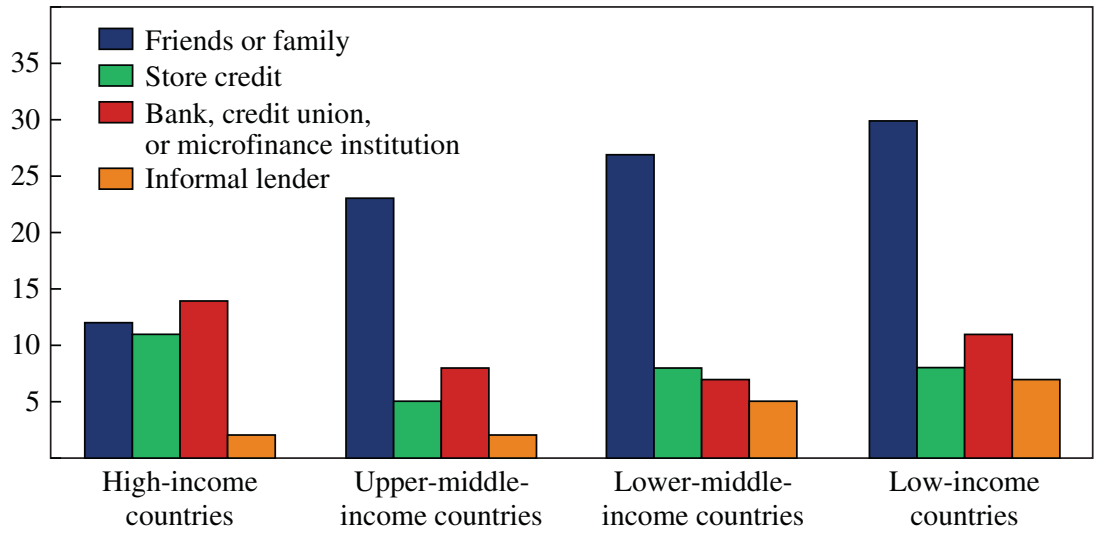

Source: Authors' calculations using Global Findex data.

a. Respondents could report borrowing from more than one source. 
more likely to report having borrowed from an informal lender other than a family member or friend in the past year. An important caveat to this finding, however, is that social norms may have a significant effect on the reporting of this type of borrowing.

The introduction of credit cards may affect the demand for and the use of short-term formal credit. In high-income countries half of the adult population report having a credit card. Despite a surge in recent years, credit card ownership in developing countries still lags far behind. Only 7 percent of adults in low- and middle-income countries report having a credit card, but there are some notable exceptions: in Brazil, Turkey, and Uruguay, for example, the proportion of adults with a credit card exceeds 35 percent.

Given the widespread ownership of credit cards in high-income countries, adults in these countries may have less need for short-term loans from financial institutions. This may help explain why the share of adults in these countries who report having received a loan in the past year from a formal financial institution is not particularly high. Indeed, if the adults in high-income countries who report owning a credit card are included in the share of those who report borrowing from a formal financial institution in the past year (a measure that may not include credit card balances), that share increases by 40 percentage points, from 14 percent to 54 percent. ${ }^{18}$ Here we focus on measures of borrowing activity that do not include credit card ownership.

Within-country relative income is also associated with formal borrowing only among developing countries (rightmost panel of table 2). On average, the difference in the origination of new formal loans over the past year between the poorest and the richest income quintile in developing countries is about 4 percent and statistically significant. Within high-income countries, in contrast, there is no significant difference across income groups on this measure.

Just as the sources of credit differ across countries and individuals, so do the purposes for which such borrowing is used. Data gathered in developing countries highlight that emergency and health needs are the most common reason for having an outstanding loan (figure 9). ${ }^{19}$ Adults in the

18. The Gallup World Poll collects information on the ownership of credit cards but not their use.

19. Data on the main purpose of outstanding loans were gathered only in developing countries, because Gallup, Inc., enforces a time limit for phone interviews conducted in high-income countries, limiting the number of questions that can be added to the core questionnaire. Respondents were asked to choose from a list of reasons for borrowing, so it is possible that reasons not listed (borrowing to start a business, for example) are also common. 
Figure 9. Purposes of Outstanding Loans in Developing Countries

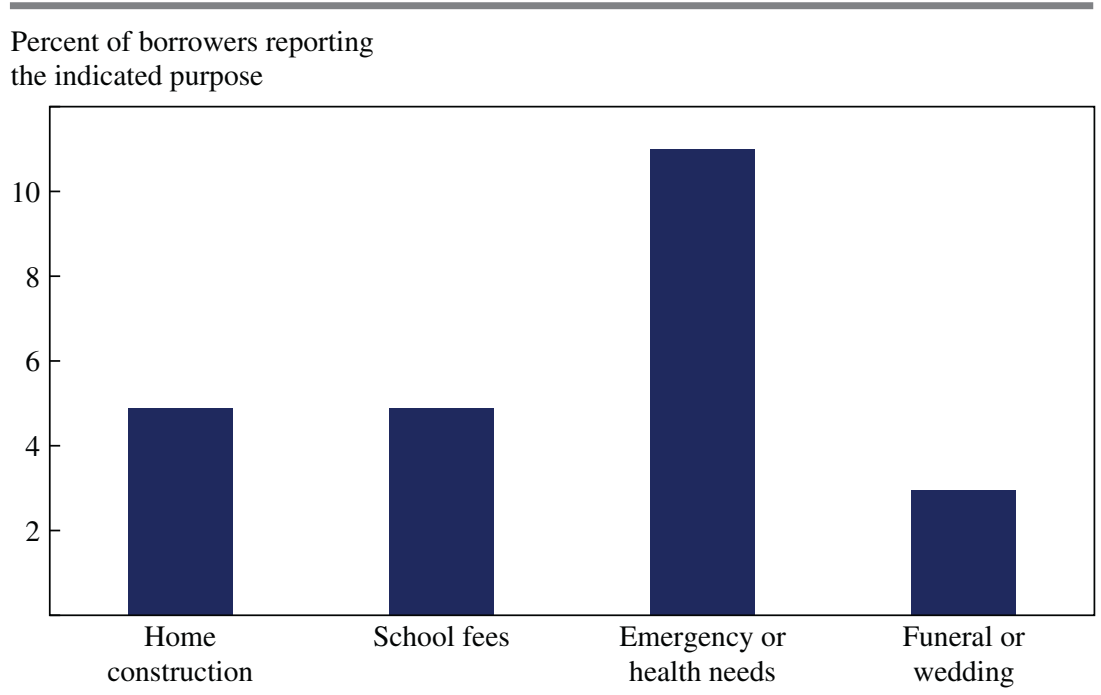

Source: Authors' calculations using Global Findex data.

poorest income quintiles also commonly report emergency and healthrelated loans. On average, in developing countries 14 percent of adults in the poorest quintile had a loan for emergency or health purposes, compared with 8 percent of those in the richest fifth of the population.

The data also highlight variation in the reasons for borrowing across regions. In sub-Saharan Africa 8 percent of adults report borrowing to pay school fees. In the developing world as a whole, outstanding loans for funerals or weddings are reported by 3 percent of adults (figure 9), but such loans are significantly more common in fragile and conflict-affected states such as Afghanistan (where the figure is 29 percent), Iraq (13 percent), Somalia (11 percent), and the West Bank and Gaza (11 percent).

Data on the use of mortgages show large differences between countries at different income levels. In high-income countries 24 percent of adults report having an outstanding loan to purchase a home; the corresponding number in developing countries is only 3 percent. Even within the European Union the use of mortgages varies widely, with very low rates of use in some of the new member states. For example, whereas 21 percent of adults in Germany have an outstanding mortgage, only 3 percent in Poland do (figure 10). Such differences may in part reflect cross-country differences in housing finance systems, such as in product diversity, types of 
Figure 10. Mortgage Penetration in Europe

Percent of adults with an outstanding loan to purchase a home or apartment

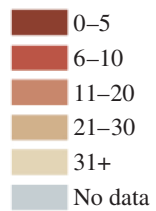

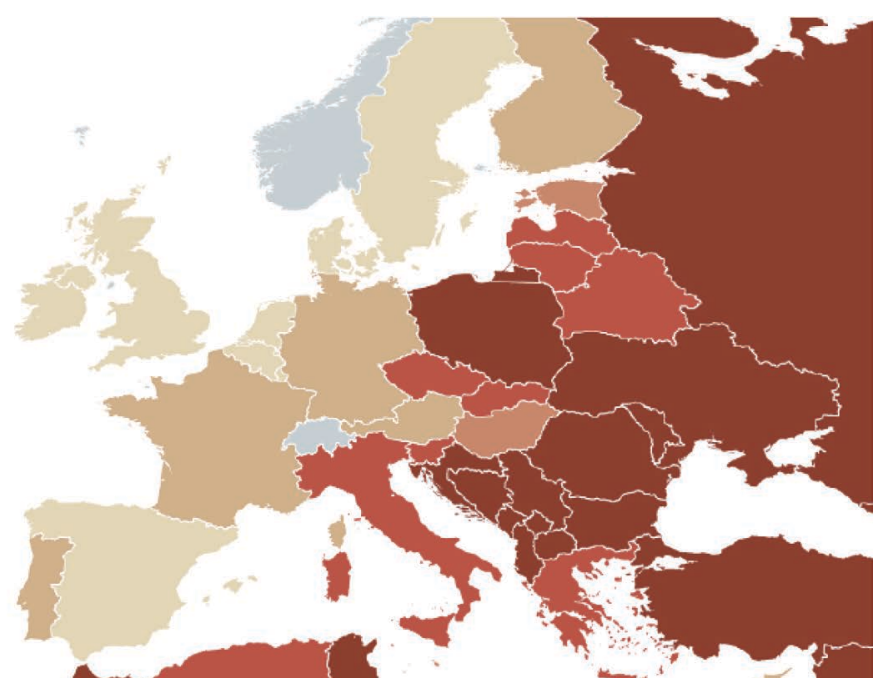

Source: Authors' calculations using Global Findex data.

lenders, secondary mortgage markets, and degree of government participation. Studies have found that these factors may affect the availability of loans to individuals (International Monetary Fund 2011). Collateral and bankruptcy laws that define the legal rights of borrowers and lenders have also been shown to affect housing finance (Warnock and Warnock 2008). And to develop fully in the first place, a mortgage market requires the existence of formal property rights and an efficient framework to record ownership of property (de Soto 2000).

\section{Barriers to Financial Inclusion}

Country income and individual characteristics clearly help explain some of the differences in the use of financial accounts around the world. But what do people themselves say when asked why they do not have an account? The Global Findex survey, by asking more than 70,000 adults without a formal account their reasons for not having one, provides novel data on the barriers to financial inclusion. In this section we discuss each self-reported barrier individually. Each represents a distinct dimension that policymakers who are aiming to expand financial inclusion can address. We also examine these self-reported barriers by country income group and individual 
Figure 11. Reported Reasons for Not Having a Bank Account ${ }^{\mathrm{a}}$

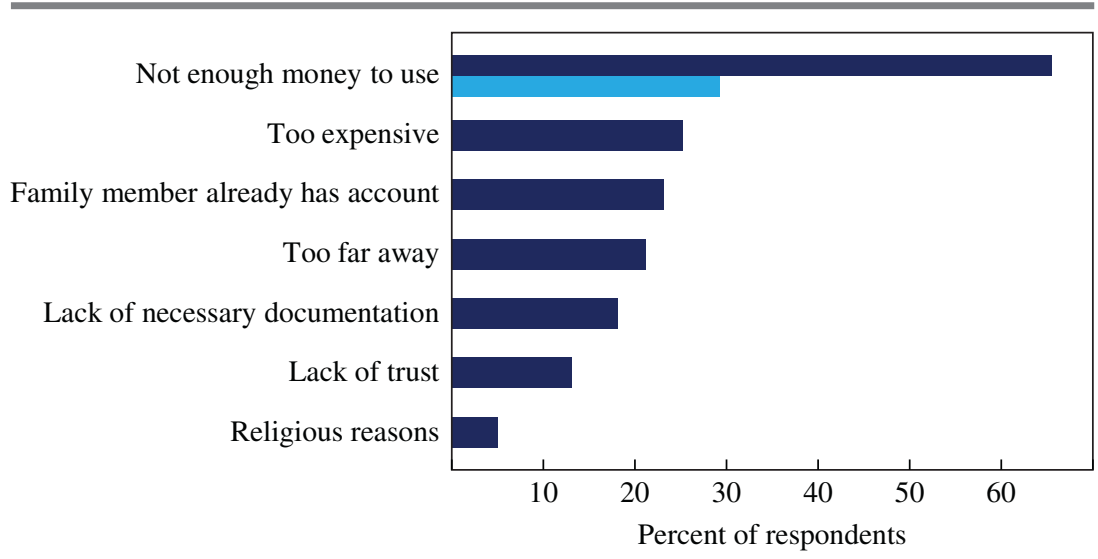

Source: Authors' calculations using Global Findex data.

a. Respondents could choose more than one reason. The lower bar for "Not enough money" refers to the percentage of adults who reported only this reason.

characteristics. This allows us to document robust relationships between subjective and objective assessments of barriers to financial access, even when accounting for GDP per capita.

Globally, the most frequently cited reason for not having a formal account is lack of enough money to use one (figure 11). This is the response given by 65 percent of adults without a formal account, and 29 percent cited this as the only reason (multiple responses were permitted) ${ }^{20}$ The next most commonly cited reasons are that banks or accounts are too expensive, and that another family member already has an account. Each of these was cited by about a quarter of adults without an account. The other reasons reported (in order of importance) are banks being too far away, lack of the necessary documentation, lack of trust in banks, and religious reasons. On average, each respondent chose 1.7 responses; the most commonly offered response combined lack of enough money to use an account with a second barrier. In low-income countries adults gave 1.91 responses, on average. Adults in these countries were significantly more likely to cite distance, cost, documentation, and lack of money than were adults in other country income groups. Lack of trust and someone else in the family already having an account were more commonly cited in middle- and high-income countries.

20. Among all respondents, 12 percent chose none of the given reasons for not having an account. 
Figure 12. Subjective and Objective Measures of Cost as a Barrier to Account Access

Countries where the cost

to open an account is ${ }^{\mathrm{a}}$

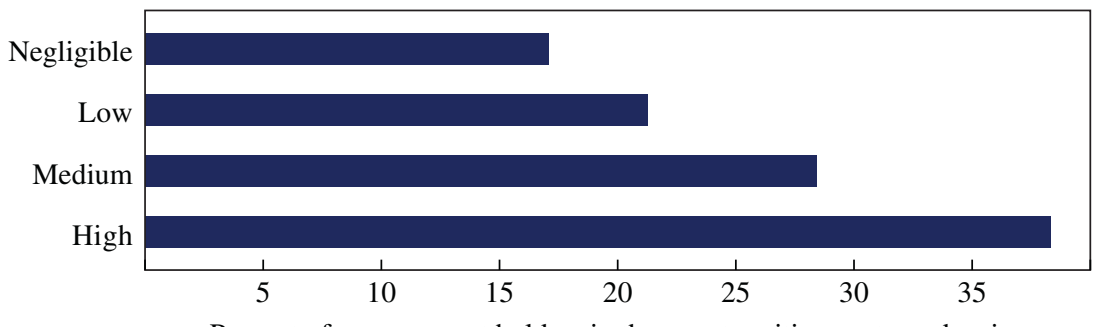

Percent of non-account holders in the country citing cost as a barrier

Source: Beck and others (2008).

a. As measured by the Annual Fees Account Index from the World Bank's Bank Regulation and Supervision Database.

At first glance it may appear that the segment of the population for whom lack of enough money is a concern is less likely to be bankable. However, those who reported this reason are likely suggesting that, under current circumstances, the costs of having an account outweigh its benefits. It seems reasonable to assume that if individuals found it easier or cheaper to use accounts, or if those accounts provided benefits such as the ability to receive remittances or government transfers, then for some of these respondents the costs associated with having an account would be outweighed by the benefits.

Affordability is also an important barrier to account ownership. High costs were cited by a quarter of unbanked respondents on average, and by 32 percent in low-income countries, where fixed transaction costs and annual fees tend to make small transactions unaffordable for large parts of the population. (Fixed fees and other high costs of opening and maintaining accounts often reflect lack of competition and underdeveloped physical or institutional infrastructure.) Maintaining a checking account in Sierra Leone, for example, costs the equivalent of 27 percent of GDP per capita in annual fees alone. So it is no surprise that 44 percent of nonaccount holders in that country cited high cost as a reason for not having a formal account. Figure 12 shows that the proportion of adults citing cost as a barrier to account ownership rises monotonically with actual costs as measured by the Annual Fees Account Index from the World Bank's Bank Regulation and Supervision Database (Beck, Demirgüç-Kunt, and Martinez Peria 2008). 
The next most commonly cited reason for not having an account (offered by 23 percent of respondents) was that another member of the family already has one. Women were significantly more likely than men to give this response, and adults in high-income and upper-middle-income countries (where relatives are most likely to have an account) were significantly more likely than those in poorer countries to choose this reason. A recent study (Hallward-Driemeier and Hasan 2013) shows that lack of account ownership (and lack of personal asset accumulation) limits women's ability to pursue self-employment opportunities. Hence, although such voluntary exclusion may be linked to individual preferences or cultural norms, it may in some cases indicate a lack of awareness of financial products or lack of financial literacy more generally. ${ }^{21}$

Twenty percent of unbanked respondents cited distance as a reason for not having a formal account. The frequency with which this barrier was cited increases sharply as one moves down the country income scale, from 10 percent in high-income countries to 28 percent in low-income countries. Among developing countries there is a significant relationship between distance as a reported barrier and objective measures of providers such as bank branch penetration. Tanzania, for example, has a large share (47 percent) of non-account holders who cited distance as a reason for not having an account, and the country ranks near the bottom in bank branch penetration, averaging less than 0.5 bank branch per 1,000 square kilometers (according to the 2010 World Bank Global Payment Systems Survey).

Documentation requirements for opening an account may also exclude workers in the rural or the informal sector, who are less likely to have wage slips or formal proof of residence. A significant relationship is seen across developing countries between subjective and objective measures of documentation requirements as a barrier to account use (figure 13); the relationship holds even after we account for GDP per capita. Indeed, the Financial Action Task Force has recognized that overly cautious safeguards against money laundering and terrorist financing can have the unintended consequence of excluding legitimate businesses and consumers from the financial system. Accordingly, the task force has emphasized the need to ensure that such safeguards also support financial inclusion, where greater inclusion is a national goal. ${ }^{22}$

21. The institutional barriers to financial inclusion are further analyzed in Allen and others (2012).

22. For more on documentation requirements and safeguards against money laundering, see Yikona and others (2011) and Financial Action Task Force (2011). 
Figure 13. Subjective and Objective Measures of Documentation Requirements as a Barrier to Account Access ${ }^{\mathrm{a}}$

Percent of non-account holders citing documentation as a barrier

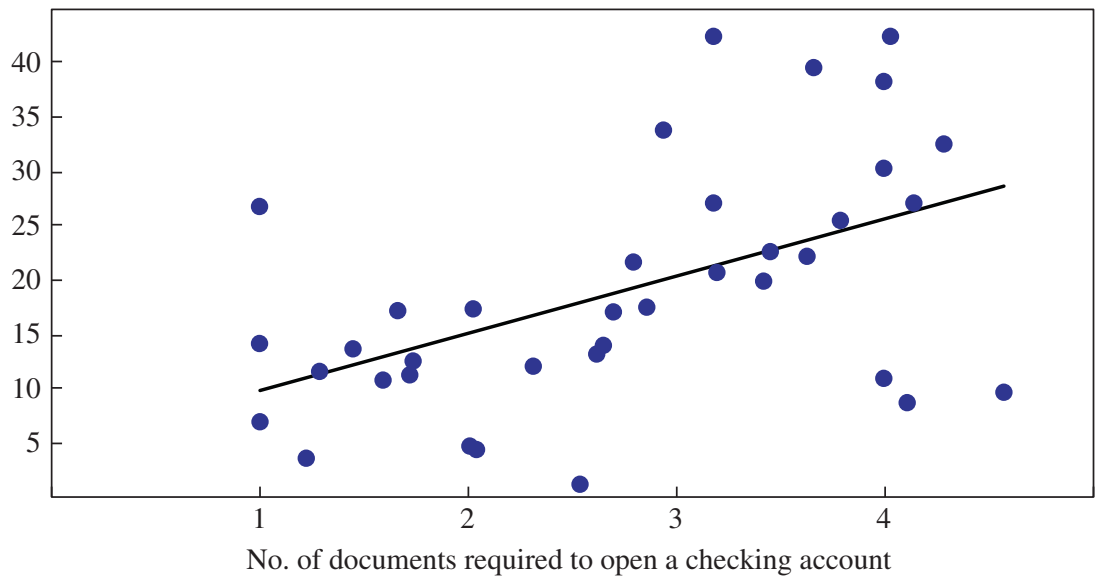

Source: Authors' calculations using Global Findex and Bank Regulation and Supervision Database (World Bank).

a. Each observation represents 1 of 37 developing countries.

Distrust in formal financial institutions is also a nontrivial barrier to wider financial inclusion, and one that is difficult to address in the short term. Thirteen percent of adults without a formal account cited lack of trust in banks as a reason why they do not own an account (figure 11). This distrust can stem from cultural norms, discrimination against certain population groups, past episodes of bank failure or government expropriation of banks, or economic crises and uncertainty. In Russia 38 percent of non-account holders cited lack of trust in banks as a reason for not having an account-approximately three times the share in developing countries on average.

Finally, only 5 percent of unbanked respondents cited religious reasons for not having a formal account, although the proportion is higher in some Middle Eastern countries such as the West Bank and Gaza and in some South Asian countries such as Pakistan. In these regions developing financial products compatible with religious beliefs (so-called Islamic finance) could potentially increase account penetration.

These systematic data on self-reported barriers to the use of financial services allow researchers and policymakers to understand the reasons for 
nonuse and provide clues for the design of policy interventions. However, such cross-sectional data cannot be used to determine the causal impact of removing these barriers. Furthermore, since people often face (and report) multiple barriers, addressing individual constraints may not necessarily expand the use of accounts if other barriers continue to bind.

\section{Mobile Money, Branchless Banking, and Beyond}

As documented in section II, there is a strong correlation between national income and financial inclusion. However, policy innovations may still be able to bring about more inclusive financial systems even at low levels of income. The Global Findex database allows us to observe how public and private sector-led initiatives might change how people engage with the formal financial system.

The success of mobile money illustrates the transformative potential of technical progress and innovation to promote financial inclusion. Mobile money - sometimes considered a form of branchless banking — has allowed people who are otherwise excluded from the formal financial system to perform financial transactions in a relatively cheap, secure, and reliable manner (Jack and Suri 2011). Individuals using mobile money maintain a type of account that allows them to make deposits and withdrawals through cash transactions at a network of retail agents. They can then transfer money or pay bills using text messages. Many mobile money accounts-such as those provided by M-PESA in Kenya or GCash in the Philippines-are not connected to an account at a financial institution, but the providers are often required to store the aggregate sums of the accounts in a bank. Customers are ordinarily charged a fee for sending money to others or making a withdrawal from their account.

Mobile money has achieved the broadest success in sub-Saharan Africa, where 16 percent of adults report having used a mobile phone in the past 12 months to pay bills or send or receive money (figure 14). The share of adults using mobile money is less than 5 percent in all other regions, but a few countries, including Haiti and the Philippines, are notable exceptions to the pattern.

The degree to which mobile money is capturing the unbanked market differs across countries. In Kenya 43 percent of adults who report having used mobile money in the past 12 months do not have a formal account. In Sudan the figure is 92 percent. This heterogeneity may reflect the varied and fast-evolving regulations surrounding mobile money. When M-PESA was launched in Kenya, it had no association with the formal banking sec- 
Figure 14. Use of Mobile Money in Africa

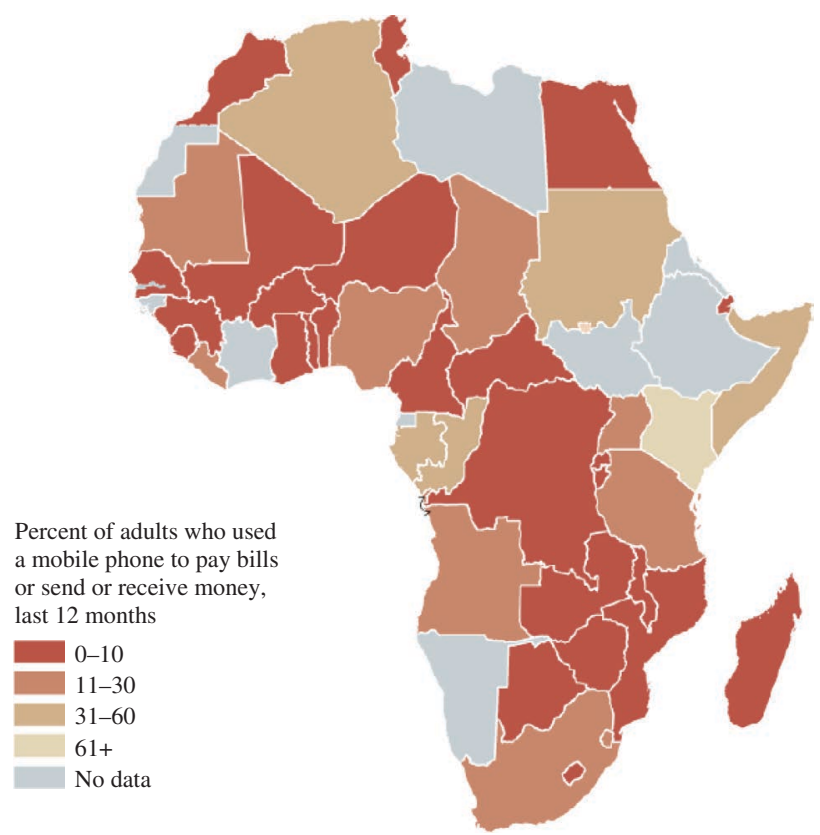

Source: Authors' calculations using Global Findex data.

tor, and mobile banking customers there were exempt from the documentation requirements imposed by banks. But governments are increasingly favoring bank-led models in which mobile money providers have partnerships with or are formed directly through banks (Consultative Group to Assist the Poor 2010).

In recent years the proliferation of branchless banking has also received growing attention as a way to increase financial access in developing countries, particularly among underserved groups (see Mas and Kumar 2008). One mode of branchless banking centers on bank agents, who often operate out of retail stores, gas stations, or post offices. By capitalizing on existing infrastructure and client relationships, operators can expand financial access in a more cost-efficient manner. Bank agents themselves can also be mobile, making daily or weekly rounds among clients. Few account holders currently report relying on bank agents (whether over the counter at a retail store or some other person associated with their bank) as their main mode of withdrawal or deposit. But in several Asian countries-including 
Bangladesh, Laos, Nepal, and the Philippines-more than 10 percent of account holders already report using bank agents.

There is also enormous scope for the public sector to bring about transformative change in how adults around the globe interact with the formal financial sector. Increasingly, governments are using formal accounts to disburse transfer payments. In Brazil the government allows recipients of conditional cash transfers (as part of its Bolsa Familia program) to receive payments via no-frills bank accounts, although many more choose to receive payments via a virtual account that does not allow deposits or indefinite storage (Consultative Group to Assist the Poor 2011). Still, according to Findex data, 20 percent of adults in Brazil report receiving government transfers via a bank account, one of the highest proportions in the developing world. In India the government recently began depositing government pension and scholarship payments directly into the bank accounts of almost 250,000 people in 20 districts. Officials plan to expand the program and hope it will prevent corruption as well as expand financial access. ${ }^{23}$ The data provide suggestive evidence that these types of reforms may have the potential to dramatically expand the reach of the formal financial sector to the poorest individuals.

\section{Conclusion}

For most people around the world, having an account at a financial institution serves as an entry point into the formal financial sector. A formal account can encourage saving and open access to credit. It can also make it easier to transfer wages, remittances, and government payments. Broadbased access to accessible and affordable formal accounts is a hallmark of an inclusive financial system, the absence of which can contribute to persistent income inequality and slower economic growth.

Yet until now little was known about the global reach of the financial sector and financial inclusion-the extent of account ownership and the use of formal payments, saving, and credit—or about the degree to which groups such as the poor are excluded from formal financial systems. Systematic indicators of the use of different formal and informal financial services were lacking for most countries.

23. Gardiner Harris, "India Aims to Keep Money for Poor Out of Others' Pockets," New York Times, January 5, 2013. 
As the first public database of indicators that consistently measure people's use of financial products across countries and over time, the Global Findex database fills a big gap in existing data on financial inclusion. The data show wide gaps in account penetration between highincome and developing countries and between the poor and the rich within countries. Also, the data show variation in the use of formal and informal saving and credit mechanisms. By enabling policymakers to identify segments of the population excluded from the formal financial sector, the data can help provide insights for the design and prioritization of reforms.

\section{APPENDIX A}

\section{Selected Questions from the Global Findex Survey}

The text of this appendix is taken verbatim from the survey.

This next section is about banks and financial institutions. We are trying to understand how people across the world use financial institutions and how available they are to people. Please remember that all information you provide is completely confidential.

-Do you, either by yourself or together with someone else, currently have an account at any of the following places? An account can be used to save money, to make or receive payments, or to receive wages and remittances. Do you currently have an account at [surveyor reads A and B] ?24

$1 \quad$ Yes

2 No

A A bank or credit union (or other formal financial institution, where applicable, like a cooperative in Latin America)

B A post office

-A debit card, sometimes called an ATM card, is a card that allows you to make payments, get money, or buy things and the money is taken out of your bank account right away. Do you have a debit card?

1 Yes

2 No

24. For all questions the choices of "don't know" and "refused" are also included as possible responses (results not shown). 
- A credit card is like a debit card but the money is not taken from your account right away. You get credit to make payments or buy things, and you can pay the balance off later. Do you have a credit card?

$1 \quad$ Yes

2 No

-In a typical month, about how many times is money deposited into your personal account(s)? This includes cash or electronic deposits, or any time money is put into your account(s) by yourself or others. [surveyor reads 1 through 4 and codes one response only]

10

$2 \quad 1-2$ times

$3 \quad 3-5$ times

46 times or more

- In a typical month, about how many times is money taken out of your personal account(s)? This includes cash withdrawals, electronic payments or purchases, checks, or any other time money is removed from your account(s) by yourself or others. [surveyor reads 1 through 4 and codes one response only]

10

$2 \quad 1-2$ times

$3 \quad 3-5$ times

46 times or more

-When you need to get cash (paper or coins) from your account(s), do you usually get it ... ? [surveyor reads 1 through 4 and codes one response only; respondents can also answer that they do not withdraw cash (coded as 5)]

1 At an ATM

2 Over the counter in a branch of your bank or financial institution

3 Over the counter at a retail store

4 From some other person who is associated with your bank or financial institution

-When you put cash (paper or coins) into your account(s), do you usually do it ... ? [surveyor reads 1 through 4 and codes one response only; respondents can also answer that they do not withdraw cash (coded as 5)]

1 At an ATM

2 Over the counter in a branch of your bank or financial institution

3 Over the counter at a retail store

4 From some other person who is associated with your bank or financial institution 
—In the past 12 months, have you used your account(s) to ... ? [surveyor reads A through D]

1 Yes

2 No

A Receive money or payments for work or from selling goods

B Receive money or payments from the government

C Receive money from family members living elsewhere

D Send money to family members living elsewhere

-Please tell me whether each of the following is a reason why you, personally, DO NOT have an account at a bank, credit union or other financial institution. [surveyor reads and rotates A through $\mathrm{G}$ ]

1 Yes

2 No

A They are too far away

B They are too expensive

C You don't have the necessary documentation (ID, wage slip)

D You don't trust them

E You don't have enough money to use them

$\mathrm{F} \quad$ Because of religious reasons

G Because someone else in the family already has an account

—In the past 12 months, have you saved or set aside any money?

1 Yes [surveyor continues with next question]

2 No [surveyor skips to question 74]

—In the past 12 months, have you saved or set aside any money by . . . ? [surveyor reads $\mathrm{A}$ and $\mathrm{B}$ ]

1 Yes

2 No

A Using an account at a bank, credit union, or microfinance institution

B Using an informal savings club or a person outside the family (insert local example)

—In the past 12 months, have you borrowed any money from ... ? [surveyor reads A through E]

$1 \quad$ Yes

2 No

A A bank, credit union, or microfinance institution

B A store by using installment credit or buying on credit

C Family or friends 
D Employer

E Another private lender

-Do you currently have a loan you took out for any of the following reasons? [surveyor reads A through E]

$1 \quad$ Yes

2 No

A To purchase your home or apartment

B To purchase materials or services to build, extend, or renovate your home or apartment

C To pay school fees

D For emergency/health purposes

E For funerals or weddings

—In the past 12 months, have you used a mobile phone to . . . ? [surveyor reads A through C]

1 Yes

2 No

A Pay bills

B Send money

C Receive money

APPENDIX B

Account Penetration by Country

Percent of adults with an account at a formal financial institution

\begin{tabular}{lcrr|lrrr}
\hline Country & $\begin{array}{c}\text { All } \\
\text { adults }\end{array}$ & $\begin{array}{c}\text { Poorest } \\
20 \%\end{array}$ & $\begin{array}{c}\text { Richest } \\
20 \%\end{array}$ & Country & $\begin{array}{c}\text { All } \\
\text { adults }\end{array}$ & $\begin{array}{c}\text { Poorest } \\
20 \%\end{array}$ & $\begin{array}{c}\text { Richest } \\
20 \%\end{array}$ \\
\hline Afghanistan & 9 & 0 & 20 & Belgium & 96 & 92 & 96 \\
Albania & 28 & 7 & 43 & Benin & 10 & 5 & 24 \\
Algeria & 33 & 22 & 50 & Bolivia & 28 & 12 & 50 \\
Angola & 39 & 31 & 40 & Bosnia and & 56 & 35 & 69 \\
Argentina & 33 & 19 & 55 & Herzegovina & & & \\
Armenia & 17 & 16 & 24 & Botswana & 30 & 12 & 48 \\
Australia & 99 & 97 & 100 & Brazil & 56 & 33 & 71 \\
Austria & 97 & 93 & 99 & Bulgaria & 53 & 29 & 76 \\
Azerbaijan & 15 & 13 & 25 & Burkina Faso & 13 & 6 & 25 \\
Bahrain & 65 & 64 & 60 & Burundi & 7 & 3 & 23 \\
Bangladesh & 40 & 33 & 54 & Cambodia & 4 & 0 & 12 \\
Belarus & 59 & 37 & 75 & Cameroon & 15 & 14 & 22
\end{tabular}




\begin{tabular}{|c|c|c|c|c|c|c|c|}
\hline Country & $\begin{array}{c}\text { All } \\
\text { adults }\end{array}$ & $\begin{array}{c}\text { Poorest } \\
20 \%\end{array}$ & $\begin{array}{c}\text { Richest } \\
20 \%\end{array}$ & Country & $\begin{array}{c}\text { All } \\
\text { adults }\end{array}$ & $\begin{array}{c}\text { Poorest } \\
20 \%\end{array}$ & $\begin{array}{c}\text { Richest } \\
20 \%\end{array}$ \\
\hline Canada & 96 & 91 & 98 & Jordan & 25 & 16 & 33 \\
\hline Central African & 3 & 1 & 9 & Kazakhstan & 42 & 30 & 55 \\
\hline Republic & & & & Kenya & 42 & 19 & 85 \\
\hline Chad & 9 & 6 & 26 & Korea, Rep. & 93 & 86 & 94 \\
\hline Chile & 42 & 19 & 68 & Kosovo & 44 & 24 & 59 \\
\hline China & 64 & 39 & 83 & Kuwait & 87 & 86 & 90 \\
\hline Colombia & 30 & 9 & 62 & Kyrgyz & 4 & 1 & 11 \\
\hline Comoros & 22 & 9 & 40 & Republic & & & \\
\hline Congo, & 4 & 0 & 18 & Laos & 27 & 16 & 27 \\
\hline Dem. Rep. & & & & Latvia & 90 & 82 & 95 \\
\hline Congo, Rep. & 9 & 1 & 20 & Lebanon & 37 & 20 & 54 \\
\hline Costa Rica & 50 & 30 & 69 & Lesotho & 18 & 8 & 29 \\
\hline Croatia & 88 & 75 & 94 & Liberia & 19 & 3 & 41 \\
\hline Cyprus & 85 & 76 & 89 & Lithuania & 74 & 66 & 87 \\
\hline Czech Republic & 81 & 70 & 88 & Luxembourg & 95 & 97 & 94 \\
\hline Denmark & 100 & 99 & 100 & Macedonia & 74 & 66 & 85 \\
\hline Djibouti & 12 & 4 & 34 & Madagascar & 6 & 1 & 19 \\
\hline Dominican & 38 & 19 & 62 & Malawi & 17 & 9 & 36 \\
\hline Republic & & & & Malaysia & 66 & 45 & 82 \\
\hline Ecuador & 37 & 22 & 61 & Mali & 8 & 4 & 18 \\
\hline Egypt & 10 & 5 & 25 & Malta & 95 & 93 & 96 \\
\hline El Salvador & 14 & 1 & 32 & Mauritania & 17 & 7 & 43 \\
\hline Estonia & 97 & 94 & 99 & Mauritius & 80 & 66 & 94 \\
\hline Finland & 100 & 99 & 100 & Mexico & 27 & 12 & 58 \\
\hline France & 97 & 96 & 100 & Moldova & 18 & 6 & 36 \\
\hline Gabon & 19 & 4 & 38 & Mongolia & 78 & 68 & 89 \\
\hline Georgia & 33 & 25 & 50 & Montenegro & 50 & 34 & 67 \\
\hline Germany & 98 & 97 & 100 & Morocco & 39 & 0 & 0 \\
\hline Ghana & 29 & 17 & 61 & Mozambique & 40 & 21 & 56 \\
\hline Greece & 78 & 75 & 85 & Nepal & 25 & 15 & 39 \\
\hline Guatemala & 22 & 8 & 52 & Netherlands & 99 & 98 & 99 \\
\hline Guinea & 4 & 2 & 10 & New Zealand & 99 & 100 & 99 \\
\hline Haiti & 22 & 4 & 49 & Nicaragua & 14 & 4 & 31 \\
\hline Honduras & 21 & 15 & 47 & Niger & 2 & 0 & 6 \\
\hline Hong Kong & 89 & 78 & 98 & Nigeria & 30 & 12 & 62 \\
\hline Hungary & 73 & 58 & 86 & Oman & 74 & 63 & 92 \\
\hline India & 35 & 21 & 56 & Pakistan & 10 & 5 & 19 \\
\hline Indonesia & 20 & 8 & 48 & Panama & 25 & 18 & 44 \\
\hline Iran & 74 & 63 & 80 & Paraguay & 22 & 4 & 51 \\
\hline Iraq & 11 & 5 & 13 & Peru & 20 & 6 & 47 \\
\hline Ireland & 94 & 88 & 97 & Philippines & 27 & 4 & 54 \\
\hline Israel & 90 & 88 & 92 & Poland & 70 & 60 & 82 \\
\hline Italy & 71 & 61 & 81 & Portugal & 81 & 64 & 87 \\
\hline Jamaica & 71 & 71 & 67 & Qatar & 66 & 47 & 80 \\
\hline Japan & 96 & 94 & 96 & Romania & 45 & 25 & 69 \\
\hline
\end{tabular}




\begin{tabular}{|c|c|c|c|c|c|c|c|}
\hline Country & $\begin{array}{c}\text { All } \\
\text { adults }\end{array}$ & $\begin{array}{c}\text { Poorest } \\
20 \%\end{array}$ & $\begin{array}{c}\text { Richest } \\
20 \%\end{array}$ & Country & $\begin{array}{c}\text { All } \\
\text { adults }\end{array}$ & $\begin{array}{c}\text { Poorest } \\
20 \%\end{array}$ & $\begin{array}{c}\text { Richest } \\
20 \%\end{array}$ \\
\hline Russia & 48 & 34 & 61 & Togo & 10 & 2 & 18 \\
\hline Rwanda & 33 & 23 & 42 & Trinidad and & 76 & 70 & 85 \\
\hline Saudi Arabia & 46 & 32 & 51 & Tobago & & & \\
\hline Senegal & 6 & 4 & 13 & Tunisia & 32 & 14 & 63 \\
\hline Serbia & 62 & 47 & 70 & Turkey & 58 & 46 & 72 \\
\hline Sierra Leone & 15 & 4 & 30 & Turkmenistan & 0 & 0 & 1 \\
\hline Singapore & 98 & 98 & 98 & Uganda & 20 & 7 & 37 \\
\hline Slovak & 80 & 66 & 85 & Ukraine & 41 & 21 & 59 \\
\hline Republic & & & & United Arab & 60 & 57 & 58 \\
\hline Slovenia & 97 & 92 & 100 & Emirates & & & \\
\hline Somalia & 31 & 12 & 58 & United & 97 & 97 & 97 \\
\hline South Africa & 54 & 35 & 78 & Kingdom & & & \\
\hline Spain & 93 & 91 & 92 & United States & 88 & 74 & 90 \\
\hline Sri Lanka & 69 & 52 & 87 & Uruguay & 24 & 7 & 49 \\
\hline Sudan & 7 & 4 & 15 & Uzbekistan & 23 & 15 & 27 \\
\hline Swaziland & 29 & 12 & 44 & Venezuela & 44 & 27 & 54 \\
\hline Sweden & 99 & 99 & 100 & Vietnam & 21 & 6 & 35 \\
\hline Syria & 23 & 20 & 28 & West Bank & 19 & 8 & 34 \\
\hline Taiwan & 87 & 77 & 90 & and Gaza & & & \\
\hline Tajikistan & 3 & 1 & 6 & Yemen & 4 & 0 & 9 \\
\hline Tanzania & 17 & 3 & 45 & Zambia & 21 & 8 & 50 \\
\hline Thailand & 73 & 64 & 87 & Zimbabwe & 40 & 22 & 63 \\
\hline
\end{tabular}

Source: Global Findex.

ACK N O W LED G M ENTS We thank Franklin Allen, Oya Pinar Ardic Alper, Thorsten Beck, Massimo Cirasino, Robert Cull, Pascaline Dupas, Maya Eden, Tilman Ehrbeck, Michael Fuchs, Xavi Gine, Markus Goldstein, Ruth GoodwinGroen, Raúl Hernández-Coss, Richard Hinz, Jake Kendall, Aart Kraay, Alexia Latortue, Sole Martinez Peria, Ignacio Mas-Ribo, Jonathan Morduch, Nataliya Mylenko, Mark Napier, Douglas Pearce, Bikki Randhawa, Liliana RojasSuárez, Richard Rosenberg, Armida San Jose, Kinnon M. Scott, Peer Stein, Gaiv Tata, Jeanette Thomas, Klaus Tilmes, Asli Togan Egrican, Augusto de la Torre, Rodger Voorhies, and Alan Winters for their valuable and substantive comments during various stages of the project. The team is also appreciative of the excellent survey execution and related support provided by Gallup, Inc., under the direction of Jon Clifton. We are especially grateful to the Bill \& Melinda Gates Foundation for providing financial support that made the collection and dissemination of the data possible. This paper was prepared with outstanding assistance from Atisha Kumar and Douglas Randall. This paper's findings, interpretations, and conclusions are entirely those of the authors and do not necessarily represent the views of the World Bank, their executive directors, or the countries they represent. The authors report no potential conflict of interest. 


\section{References}

Allen, Franklin, Aslı Demirgüç-Kunt, Leora Klapper, and Maria Soledad Martinez Peria. 2012. "The Foundations of Financial Inclusion: Understanding Ownership and Use of Formal Accounts.” Policy Research Working Paper no. 6290. Washington: World Bank.

Ashraf, Nava, Diego Aycinena, Claudia Martinez A., and Dean Yang. 2010. "Remittances and the Problem of Control: A Field Experiment among Migrants from El Salvador." University of Michigan.

Aterido, Reyes, Thorsten Beck, and Leonardo Iacovone. 2011. "Gender and Finance in Sub-Saharan Africa: Are Women Disadvantaged?" Policy Research Working Paper no. 5571. Washington: World Bank.

Banerjee, Abhijit, Esther Duflo, Rachel Glennerster, and Cynthia Kinnan. 2010. "The Miracle of Microfinance? Evidence from a Randomized Evaluation." MIT Bureau for Research and Economic Analysis of Development Working Paper no. 278. Massachusetts Institute of Technology.

Beck, Thorsten. 2009. "FinAccess 2009: Trends, Analysis and Policy Conclusions." Consultant report for FSD Trust Kenya, Nairobi.

Beck, Thorsten, and Martin Brown. 2011. "Use of Banking Services in Emerging Markets: Household-Level Evidence." European Banking Center Discussion Paper no. 2011-024. Tilburg University, the Netherlands.

Beck, Thorsten, Aslı Demirgüç-Kunt, and Ross Levine. 2007. "Finance, Inequality, and the Poor." Journal of Economic Growth 12, no. 1: 27-49.

Beck, Thorsten, Aslı Demirgüç-Kunt, and Maria Soledad Martinez Peria. 2007. "Reaching Out: Access to and Use of Banking Services across Countries." Journal of Financial Economics 85, no. 2: 234-66.

_. 2008. "Banking Services for Everyone? Barriers to Bank Access and Use around the World." World Bank Economic Review 22, no. 3: 397-430.

Beck, Thorsten, Ross Levine, and Norman Loayza. 2000. "Finance and the Sources of Growth." Journal of Financial Economics 58, no. 1: 261-300.

Campbell, John. 2006. "Household Finance." Journal of Finance 61, no. 4: 1553-1604.

Chawla, Mukesh, Gordon Betcherman, and Anne Banerji. 2007. From Red to Gray: The "Third Transition" of Aging Populations in Eastern Europe and the Former Soviet Union. Washington: World Bank.

Chen, Shaohua, and Martin Ravallion. 2010. "The Developing World Is Poorer Than We Thought but No Less Successful in the Fight against Poverty." Quarterly Journal of Economics 125, no. 4: 1577-1625.

Clausen, Bianca, Aart Kraay, and Zsolt Nyiri. 2011. "Corruption and Confidence in Public Institutions: Evidence from a Global Survey." World Bank Economic Review 25, no. 2: 212-49.

Cole, Shawn, Thomson Sampson, and Bilal Zia. 2011. "Prices or Knowledge? What Drives Demand for Financial Services in Emerging Markets?" Journal of Finance 66, no. 6: 1933-67. 
Collins, Daryl, Jonathan Morduch, Stuart Rutherford, and Orlando Ruthven. 2009. Portfolios of the Poor: How the World's Poor Live on Two Dollars a Day. Princeton University Press.

Consultative Group to Assist the Poor (CGAP). 2010. "Technology Program Focus Country: India." Washington.

—. 2011. "CGAP G2P Brazil Country Report." Washington.

Cull, Robert, Aslı Demirgüç-Kunt, and Jonathan Morduch. 2013. Banking the World: Empirical Foundations of Financial Inclusion. MIT Press.

Deaton, Angus 2008. "Income, Health, and Well-Being around the World: Evidence from the Gallup World Poll." Journal of Economic Perspectives 22, no. 2: 53-72.

Demirgüç-Kunt, Aslı, and Leora Klapper. 2012. "Measuring Financial Inclusion: The Global Findex Database.” Policy Research Working Paper no. 6025. Washington: World Bank.

Demirgüç-Kunt, Aslı, and Ross Levine. 2009. "Finance and Inequality: Theory and Evidence." Annual Review of Financial Economics 1: 287-318.

Demirgüç-Kunt, Aslı, Leora Klapper, Peter Van Oudheusden, and Luigi Zingales. 2013. "Trust in Banks." Working paper. Washington: Development Research Group, World Bank.

De Soto, Hernando. 2000. The Mystery of Capital: Why Capitalism Triumphs in the West and Fails Everywhere Else. New York: Random House.

Djankov, Simeon, Caralee McLiesh, and Andrei Shleifer. 2007. "Private Credit in 129 Countries.” Journal of Financial Economics 2, no. 84: 299-329.

Dupas, Pascaline, and Jonathan Robinson. 2009. "Savings Constraint and Microenterprise Development: Evidence from a Field Experiment in Kenya." Working Paper no. 14693. Cambridge, Mass.: National Bureau of Economic Research.

—. 2011. "Why Don't the Poor Save More? Evidence from Health Savings Experiments.” Working Paper no. 17255. Cambridge, Mass.: National Bureau of Economic Research.

European Bank for Reconstruction and Development (EBRD). 2011. Life in Transition: After the Crisis. London.

Financial Action Task Force (FATF). 2011. FATF Guidance on Anti-Money Laundering and Terrorist Financing Measures and Financial Inclusion. Paris: FATF/OECD.

Federal Deposit Insurance Corporation (FDIC). 2011. FDIC National Survey of Unbanked and Underbanked Households. Washington.

Hallward-Driemeier, Mary, and Tazeen Hasan. 2013. Empowering Women: Legal Rights and Economic Opportunities in Africa. Development Forum Series. Paris: Agence Française de Développement, and Washington: World Bank.

Honohan, Patrick. 2008. "Cross-Country Variation in Household Access to Financial Services." Journal of Banking and Finance 32: 2493-2500.

International Monetary Fund (IMF). 2011. Global Financial Stability Report: Grappling with Crisis Legacies, September 2011. Washington. 
Jack, William, and Tavneet Suri. 2011. "Mobile Money: The Economics of M-PESA.” Working Paper no. 16721. Cambridge, Mass.: National Bureau of Economic Research.

Johnston, Don, and Jonathan Morduch. 2008. "The Unbanked: Evidence from Indonesia." World Bank Economic Review 22, no. 3: 517-37.

Karlan, Dean, and Jonathan Zinman. 2010. "Expanding Credit Access: Using Randomized Supply Decisions to Estimate the Impacts." Review of Financial Studies 23, no. 1: 433-64.

King, Robert G., and Ross Levine. 1993. "Finance and Growth: Schumpeter Might Be Right." Quarterly Journal of Economics 108, no. 3: 717-37.

Klapper, Leora, and Inessa Love. 2011. "The Impact of the Financial Crisis on New Firm Registration.” Economics Letters 113: 1-4.

Klapper, Leora, Luc Laeven, and Raghuram Rajan. 2006. "Entry Regulation as a Barrier to Entrepreneurship." Journal of Financial Economics 82: 591-629.

Mas, Ignacio, and Kabir Kumar. 2008. "Banking on Mobiles: Why, How, for Whom?" Focus Note no. 48. Washington: Consultative Group to Assist the Poor.

Ratha, Dilip. 2006. "Leveraging Remittances for Development." In Migration, Trade, and Development, proceedings of a conference sponsored by the Federal Reserve Bank of Dallas, The Tower Center for Political Studies, the Department of Economics at Southern Methodist University, and the Jno E. Owens Foundation (October).

Sacks, Daniel, Betsey Stevenson, and Justin Wolfers. 2010. "Subjective Well-Being, Income, Economic Development and Growth." Working Paper no. 16441. Cambridge, Mass.: National Bureau of Economic Research.

Stevenson, Betsey, and Justin Wolfers. 2008. "Economic Growth and Subjective Well-Being: Reassessing the Easterlin Paradox.” BPEA, no. 1: 1-102.

— 2011. "Trust in Public Institutions over the Business Cycle." American Economic Review Papers and Proceedings 101, no. 3: 281-87.

Warnock, Veronica C., and Francis E. Warnock. 2008. "Markets and Housing Finance." Journal of Housing Economics 17, no. 3: 239-51.

World Bank. 2008a. Finance for All? Policies and Pitfalls in Expanding Access. Washington.

—. 2008b. Global Purchasing Power Parities and Real Expenditures: 2005 International Comparison Program. Washington.

Yikona, Stuart, Brigitte Slot, Michael Geller, Bjarne Hansen, and Fatima el Kadir. 2011. Ill-Gotten Money and the Economy: Experiences from Malawi and Namibia. Washington: World Bank. 


\section{Comments and Discussion}

\section{COMMENT BY}

PASCALINE DUPAS The new Global Findex data set that Asl1 Demirgüç-Kunt and Leora Klapper are introducing in this paper is arguably among the most important multicountry, repeated-cross-sectional data sets being collected in this decade. It provides much-needed statistics on the use of financial services around the world at a time when interest in such services is peaking. Indeed, almost 40 years after Muhammad Yunus made the first microloan - the first of many exciting developments in financial services for the poor-only now are we beginning to see concerted research efforts to map the reach and effect of these tools on households around the world.

Country-specific micro-level studies have suggested that financial inclusion today may be much lower than what an informed observer would suppose from the ubiquitous media accounts. For example, recent randomized trials suggest that at best a quarter of households take up available loans from microfinance institutions in India, Mexico, and Morocco (Banerjee and others 2013, Crépon and others 2011, Angelucci, Karlan, and Zinman 2012). Dupas and coauthors (forthcoming) document that only 20 percent of households in rural western Kenya have a bank account, and ongoing censuses in Uganda and Malawi reveal comparable rates (see Dupas, Karlan, and Robinson 2013). But such micro studies tend to be clustered in a few countries or areas, and absent more wide-reaching data, it is difficult to understand how representative and applicable these results are. Efforts to date to provide more-exhaustive survey evidence have remained limited: the FinScope survey sponsored by the U.K. Department for International Development covers only 15 countries (14 of them in Africa), and the European Bank for Reconstruction and Development's Life in Transition Survey covers only 35 countries in Europe and Central Asia. 
Given the lack of survey evidence, until the Global Findex data set was introduced, the most extensive efforts to estimate rates of financial inclusion worldwide had to rely on triangulation exercises between aggregate banking data from bank regulators and microfinance institutions (to get absolute numbers of accounts, loans, and the like) and population counts. Thorsten Beck, Demirgüç-Kunt, and Ross Levine (2007) focus on the formal banking sector and estimate that across the 54 countries in their sample, the median number of deposit accounts per 1,000 people is 529, and across a subset of 44 of those countries, the median number of loans per 1,000 people is 80. Patrick Honohan (2008) builds on this effort and proposes a "composite indicator" of access to both formal and semiformal financial services. This indicator is constructed from estimates of the number of bank accounts and the size of deposits relative to the total population. These estimates are generated as functions of the number of microfinance accounts and GDP per capita, respectively; these functions in turn are based on correlations observed in the few countries with enough available data.

The first thing that can be done with the Global Findex database is to check the accuracy of such extrapolation exercises. Because the Honohan (2008) estimates are from 5 to 8 years before the Global Findex measures, one should not expect a perfect correlation between the two, but after downloading both sets of measures, I found the correlation to be surprisingly high: 0.85 between Honohan's estimate of "access to financial services" (Honohan 2008, table 2) and the share of the population that "has an account at a formal financial institution" in the Global Findex database (see figure 3 in the paper). What is more, further calculations by Alberto Chaia and coauthors (2009) based on Honohan's figures find that (as their title states) "half the world is unbanked," which is also a key finding from the Global Findex. I found this high rate of consistency across the two types of sources to be very good news: it means that estimation exercises like those of Beck and others (2007), Honohan (2008), and Chaia and others (2009) are relatively accurate in providing comparable cross-country measures.

But gauging and analyzing covariates of cross-country variation can take one only so far toward a better understanding of financial inclusion worldwide. A key advantage of the Global Findex is that it provides information on within-country distributions, as well as on basic individual-level covariates of financial inclusion such as income, attitudes toward formal banks, and self-reported reasons for using or not using a given financial tool or service. The paper highlights a few of the many interesting patterns that the data uncover. For example, the authors report that 13 percent 
of unbanked adults worldwide mention lack of trust as a reason for not saving with a formal institution. This suggests that reliability and quality concerns about the supply side, as also highlighted for the specific context of western Kenya in Dupas and others (2012), are relevant in a number of other countries, especially in Africa and South Asia. Another stunning statistic from the Global Findex is the extremely low (6 percent) rate of coverage with rainfall, crop, or livestock insurance among those in developing economies whose livelihood is farming, fishing, or forestry. Yet another interesting finding is that mobile money services are, at least initially, disproportionately used by those already banked. (In Kenya, the pioneer in terms of mobile money, 57 percent of mobile money users have a formal bank account, compared with a population mean of 42 percent.) Having access to such basic statistics will help shape the financial inclusion research agenda for years to come.

The other extremely appealing feature of the Global Findex data is that they are set to be collected triennially for at least three rounds. The first round, analyzed in this paper, took place in 2011, and two rounds will follow in 2014 and 2017. The timing is particularly fortuitous: the first round was collected before the mobile money "revolution" really took hold: the survey reveals that as of 2011, only 16 percent of African adults had ever used mobile money, and fewer than 5 percent of adults in all other regions had. By 2014 this percentage will likely have increased considerably. The Global Findex data set will therefore provide a series of snapshots over a tremendously exciting decade, during which the definition of financial inclusion itself may change as new tools such as mobile phone-based savings accounts are further developed and adopted. Among other things, the data will help advance research into how these new financial tools interact with the more established tools and services.

The data set is a major advance, but there remains scope for improvement in the next round of surveying. One such improvement would be to add some measurement of "financial fragility." In a recent Brookings Paper, Annamaria Lusardi, Daniel Schneider, and Peter Tufano (2011) examined this issue for U.S. households by looking at households' capacity to raise $\$ 2,000$ in 30 days. The authors found that nearly half of the households surveyed would probably not be able to do so. Adding a similar question to the Global Findex survey would enable researchers to examine how financial inclusion correlates with financial fragility. In the existing Global Findex survey, households are not asked whether they are credit rationed, nor are they asked anything about the size of their current savings. Asking people directly how much they have in savings may be too 
Table 1. Survey Evidence on Financial Fragility in Kenya, Malawi, and Uganda Percent of respondents

\begin{tabular}{|c|c|c|c|}
\hline \multirow[b]{2}{*}{ Answer ${ }^{\mathrm{a}}$} & \multicolumn{3}{|c|}{$\begin{array}{l}\text { "If you had an emergency that required [indicated } \\
\text { amount] urgently, where you would get the money?" }\end{array}$} \\
\hline & $\begin{array}{c}\text { Kenya } \\
(1,000 \text { shillings } \\
\approx \$ 12)\end{array}$ & $\begin{array}{c}\text { Malawi } \\
(1,000 \text { kwacha } \\
\approx \$ 7)\end{array}$ & $\begin{array}{c}\text { Uganda } \\
(10,000 \text { shillings } \\
\approx \$ 5)\end{array}$ \\
\hline $\begin{array}{l}\text { Would borrow from friends or } \\
\text { relatives }\end{array}$ & 43 & 39 & 50 \\
\hline Would sell agricultural products & 14 & 3 & 9 \\
\hline Would work more & 14 & 21 & 9 \\
\hline Would sell assets & 14 & 7 & 14 \\
\hline Would exclusively use savings & 13 & 7 & 15 \\
\hline Would borrow from savings club & 6 & 3 & 2 \\
\hline $\begin{array}{l}\text { Would not be able to find the } \\
\text { money }\end{array}$ & 0 & 18 & 0 \\
\hline
\end{tabular}

Source: Household survey data collected by the author and Jonathan Robinson along with Anthony Keats (Kenya, 2010), Dean Karlan, and Diego Ubfal (Malawi and Uganda, 2011) for ongoing projects.

a. Respondents could give more than one answer.

sensitive and prone to underreporting, but asking whether and how they could access a given sum (which would have to be adjusted to the context, for example by keeping the ratio to the local poverty line constant) would be a great, if indirect, way to get a sense of how deep financial inclusion is. In ongoing work, some colleagues and I asked such a question of unbanked rural households in Kenya, Malawi, and Uganda between 2010 and 2012. The results, presented in table 1, show that most of the poor households in our various samples have very limited savings, and that an individual's financial resources are to a great extent a function of the depth of that individual's social network.

The data reported in table 1 resonate with the present paper's finding that 65 percent of non-account owners mention "not having enough money to use one" as one reason for not using a bank account (with close to half of them reporting it as their only reason). Demirgüç-Kunt and Klapper interpret this as evidence that "under current circumstances, the costs of having an account outweigh its benefits" (emphasis in the original). They also write that this finding "speaks to the fact that having a formal account is not costless in most parts of the world and that individuals with small or irregular income streams might view an account as an unnecessary expense, given the relatively high cost." I would like to qualify this interpretation. Work that coauthors and I have done in Kenya and other parts of 
East Africa suggests that individuals reporting "not having enough money" to use an account would not necessarily immediately start using accounts provided to them completely free of charge. In Kenya, Jonathan Robinson and I have found that very few bicycle-taxi drivers actively took up (that is, made at least two deposits within a year in) accounts that they could open at no cost to themselves, whereas about 40 percent of market vendors did (Dupas and Robinson 2013a). More generally, only 18 percent of a representative sample of unbanked households actively used accounts that were free to open and maintain (Dupas and others 2012). Replication studies ongoing in Uganda and Malawi suggest rates no higher than 30 percent. The fact that these accounts have withdrawal fees may be part of the explanation for the low take-up, but many households do not report fees as a barrier, instead simply stating that they do not have enough money to save. But when provided with lockboxes (a simple metal box with a deposit slit on top and a lock and key), the same Kenyan households mentioned above made very regular deposits and saved in just 3 months as much as would have taken them 18 months to save in an account. Thus, households were in fact able to save more than they themselves thought they could. This may be due to a feature that lockboxes offer that formal accounts may not. In essence, access to these in-house savings tools make people pennywise: they provide a place to store amounts that are too small to warrant a trip to the bank, thus safeguarding funds that would otherwise be kept close at hand and so be at risk of being frittered away on unplanned small expenditures, such as sweets for the children or soda for visitors. ${ }^{1}$

What this all means is that not having enough money to warrant a trip to the bank to deposit it is itself a function of financial inclusion, defined more broadly to encompass use of informal financial tools that facilitate the day-to-day management of even very small sums, helping to grow them into bankable lump sums. The stunning findings from the Global Findex suggest that a better understanding of what type of tools can help unbanked households save as much as they need in order to become "bankable" is an important avenue for future research. Demirgüç-Kunt and Klapper have provided the scientific community a much needed database and tool, and I hope that they will make each wave of data easily available online through a one-click download.

1. Dupas and Robinson (2013b) show that similar boxes enable households to reach a given savings goal much faster. 


\section{REFERENCES FOR THE DUPAS COMMENT}

Angelucci, Manuela, Dean Karlan, and Jonathan Zinman. 2012. "Win Some Lose Some? Evidence from a Randomized Microcredit Program Placement Experiment by Compartamos Banco.” J-PAL working paper. Abdul Latif Jameel Poverty Action Lab, Massachusetts Institute of Technology.

Banerjee, Abhijit, Esther Duflo, Rachel Glennerster, and Cynthia Kinnan. 2013. "The Miracle of Microfinance? Evidence from a Randomized Evaluation.” Working paper. Massachusetts Institute of Technology and Northwestern University.

Beck, Thorsten, Aslı Demirgüç-Kunt, and Ross Levine. 2007. "Finance, Inequality and Poverty: Cross Country Evidence." Journal of Economic Growth 12, no. 1: 211-52.

Chaia, Alberto, Aparna Dalal, Tony Goland, Maria Jose Gonzalez, Jonathan Morduch, and Robert Schiff. 2009. "Half the World is Unbanked." Framing Note. Financial Access Initiative. www.microfinancegateway.org/gm/document1.9.40671/25.pdf.

Crépon, Bruno, Esther Duflo, Florencia Devoto, and William Pariente. 2011. "Impact of Microcredit in Rural Areas of Morocco: Evidence from a Randomized Evaluation.” J-PAL working paper. Abdul Latif Jameel Poverty Action Lab, Massachusetts Institute of Technology.

Dupas, Pascaline, and Jonathan Robinson. 2013a. "Savings Constraint and Microenterprise Development: Evidence from a Field Experiment in Kenya." American Economic Journal: Applied Economics 5, no. 1: 163-92.

_. 2013b. "Why Don't the Poor Save More? Evidence from Health Savings Experiments." American Economic Review 103, no. 4: 1138-71.

Dupas, Pascaline, Dean Karlan, and Jonathan Robinson. 2013. "Expanding Access to Formal Savings Accounts in Malawi, Uganda, Chile, and the Philippines." New Haven, Conn.: Innovations for Poverty Action. www.poverty-action.org/ project/0477.

Dupas, Pascaline, Sarah Green, Anthony Keats, and Jonathan Robinson. Forthcoming. "Challenges in Banking the Rural Poor: Evidence from Kenya's Western Province." In NBER Volume on African Economic Successes, edited by S. Johnson, S. Edwards, and D. Weil. University of Chicago Press.

Honohan, Patrick. 2008. "Cross-Country Variation in Household Access to Financial Services.” Journal of Banking and Finance 32: 2493-2500.

Lusardi, Annamaria, Daniel Schneider, and Peter Tufano. 2011. "Financially Fragile Households: Evidence and Implications.” BPEA (Spring): 83-134.

\section{COMMENT BY}

LILIANA ROJAS-SUÁREZ This paper by Aslı Demirgüç-Kunt and Leora Klapper makes an important contribution to the literature by making public, and providing the first analysis of data from, the Global Findex, a new World Bank database comprising a variety of indicators on the use of financial products by individuals around the world. The database was 
constructed from 2011 survey data collected in interviews by Gallup, Inc., with selected adults in 148 countries.

Before Global Findex, the available data on the characteristics of populations excluded from formal financial institutions remained scarce and limited to a few regional efforts. ${ }^{1}$ Despite widespread recognition of the welfare and efficiency benefits associated with improved financial inclusion, and despite the large number of initiatives, public and private, already in place around the world aiming to increase the percentage of the population (households and firms) with access to financial services, ${ }^{2}$ crosscountry analyses faced severe constraints due to lack of comparable data.

In my view, one cannot overstate the importance of this new database. Not only does it open up wide-ranging possibilities for future research, but it also supports the efforts of policymakers, multilateral organizations, and private donors, who now have a new tool to guide their policies and activities for improving financial inclusion. In this regard, the authors' plans to update the survey in a couple of years are of particular importance.

This paper is part of a series of analytical papers by the authors and their colleagues that utilize the Global Findex database. The authors present and analyze some key stylized facts derived from the survey, with a significant focus on within-country differences in financial inclusion based on individual characteristics. Their results are consistent with previous (scattered) evidence, and from that perspective they validate a number of policymakers' concerns. For example, as expected, the authors find that the percentage of individuals in developing countries who have an account at a formal financial institution increases by income quintile; this is not the case in most developed economies, where a large majority of the population at all income levels have access to such financial products. Moreover, across

1. As the authors note, two of the best-known household surveys that include data on the use of financial services are FinScope, a private sector initiative funded by the U.K. Department for International Development, which collects data for 14 African countries and Pakistan, and the European Bank for Reconstruction and Development's Life in Transition Survey, which covers 35 countries in Europe and Central Asia. To these may be added the recent survey by CAF Banco de Desarrollo de América Latina (2011) that covers 17 major Latin American cities.

2. Ongoing initiatives go beyond microfinance activities and include innovations to improve the use of payments, savings, and insurance products. Two of the best-known initiatives are Kenya's M-PESA money transfer service (operated by a mobile phone provider) and the nonbank correspondent model in Brazil, which allows banks to reach remote populations through the use of existing nonbank networks, such as retail stores and post offices. A common characteristic of these two initiatives is that they rely heavily on technological advances in connectivity. 
the developing world, the percentage of adult women with an account at a formal financial institution is significantly below that for men, and this gender gap persists across income levels (quintiles) within a given country.

The Global Findex data can be used for many other kinds of analysis. My own research has already benefited from the availability of this new database. Like the authors, I am interested in understanding the determinants of the use of financial products, and I have gained some further insights by focusing on the cross-country behavior of variables at the macro (aggregate) level. These findings, which I will summarize here, complement the authors' results.

The existing literature allows one to identify four categories of obstacles to financial inclusion at the country level, which affect either the demand for or the supply of financial services or both (see Rojas-Suárez and Gonzales 2010 and Rojas-Suárez and Amado forthcoming): socioeconomic constraints, macroeconomic factors, characteristics of the operations of the formal financial system, and institutional deficiencies. Here I will present and discuss some simple correlations between these obstacles and one of the Global Findex indicators of financial inclusion, namely, the percentage of the adult population with an account at a formal institution.

With regard to the first category, it is generally expected that countries that score high on indicators of social development, such as access to high-quality health and education services, will also enjoy high levels of financial inclusion. As discussed by Stijn Claessens (2005), financial exclusion is often part of a broader social exclusion, which is related, among other factors, to differences in education, type of employment, and training. Income inequality has also been cited as a socioeconomic factor influencing financial inclusion. Yet another factor, one that affects both the demand for and the supply of financial services, is the percentage of the population classified as middle class (see Rojas-Suárez and Amado forthcoming for further discussion).

My figure 1 shows the correlation between financial inclusion and an index of social development, constructed by equally weighting the first two of the three components of the Human Development Index (HDI) of the United Nations, which relate to health and education (the third relates to income). The figure shows a strong positive correlation: as expected, the developed countries display the highest values of both financial inclusion and social development. The very high correlation between our social development variable and GDP per capita (0.84) supports the authors' finding that the latter explains a significant part of the variation in account penetration across countries. 
Figure 1. Financial Inclusion and Social Development

Percent of adults with a formal financial account

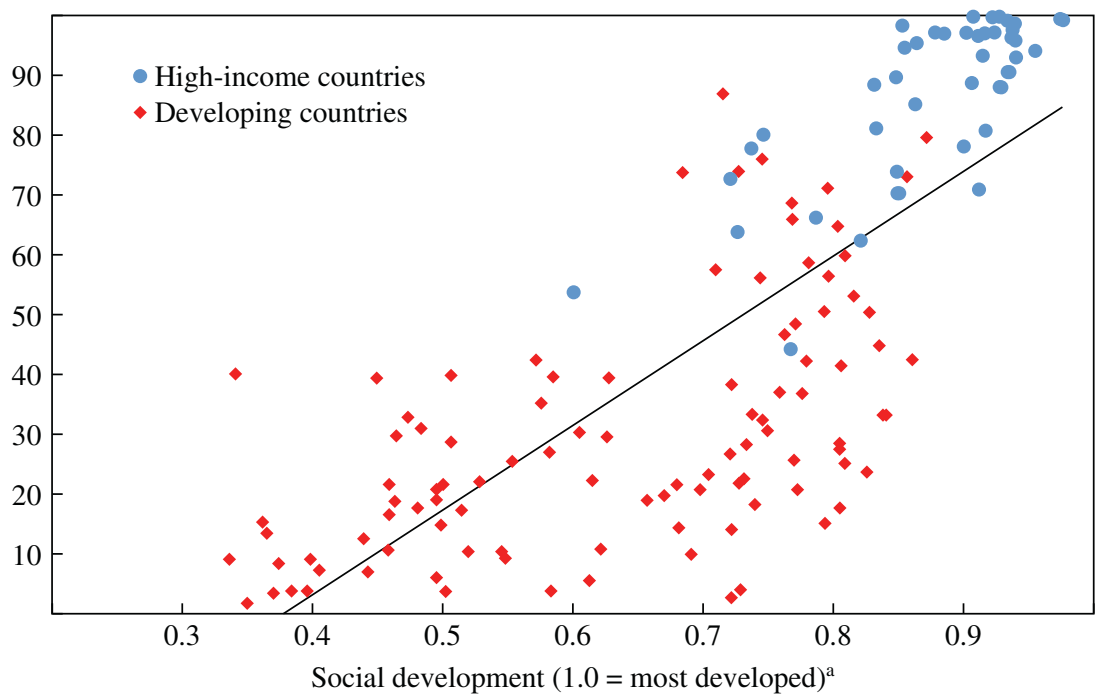

Sources: Global Findex data and United Nations Development Programme (UNDP) data.

a. Constructed as a simple average of the health (life expectancy) and education components of the 2011 Human Development Index of the United Nations Development Programme. The line in the figure is the best-fit line from a linear regression in which the percent of adults with a formal financial account is the dependent variable.

Turning to the second category affecting financial inclusion, namely, macroeconomic factors, I show in figure 2 the correlation between the volatility of inflation (measured as the coefficient of variation of inflation during 1990-2010) and financial inclusion. High volatility of inflation captures well the adverse effects of macroeconomic instability on the willingness of the population to hold accounts in formal financial institutions. In economies with very high and volatile inflation, depositors have experienced significant losses in their real wealth. It is therefore not surprising that Argentina and Ukraine, both of which suffered from hyperinflation in the 1990s, are among the countries with the lowest rates of financial inclusion. By contrast, in Thailand, which has a history of low inflation volatility, the share of the adult population with an account at a formal financial firm is similar to that in the developed countries.

The policy lesson is straightforward: stimulating demand for financial services requires that individuals have trust that the real value of their payments and savings instruments will be preserved. If this trust is lacking, 
Figure 2. Financial Inclusion and Inflation Volatility ${ }^{\mathrm{a}}$

Percent of adults with a formal financial account

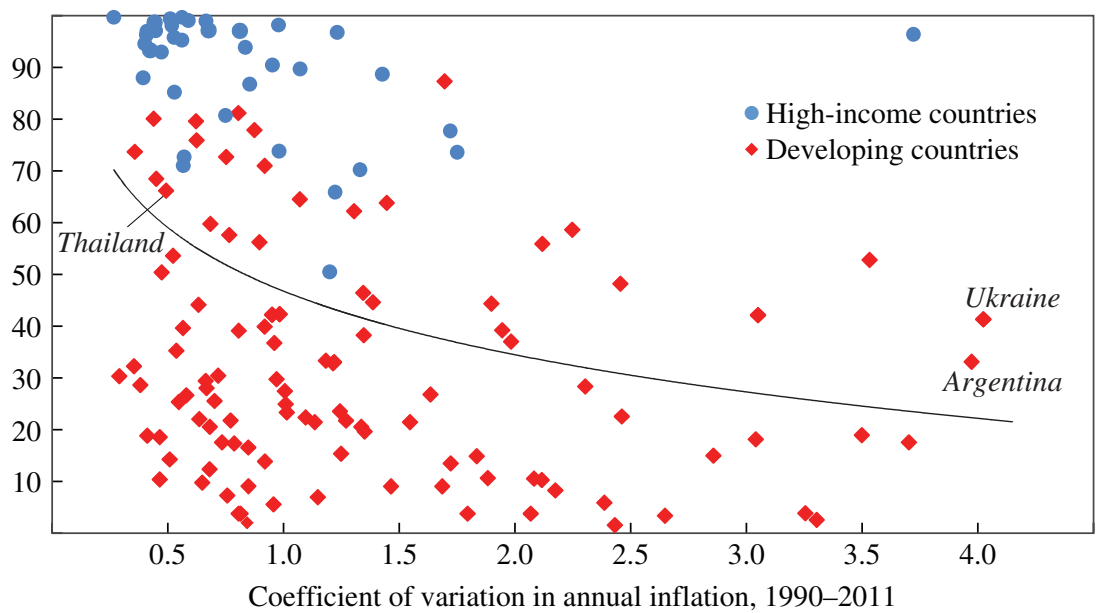

Source: Based on Rojas-Suárez and Amado (forthcoming) using Global Findex data and International Monetary Fund (World Economic Outlook) data.

a. The line in the figure is the best-fit line from a logarithmic regression in which the percent of adults with a formal financial account is the dependent variable.

not only will the use of financial services remain dismal, but deposits in financial institutions will tend to be short-term as depositors stand ready to withdraw their funds at the first sign of financial system difficulties.

A wide variety of characteristics pertaining to financial firms' conduct of their operations are included in the third category of obstacles to financial inclusion. Among these are inefficiencies in collection and information processing, which may cause prohibitively high documentation requirements; insufficient numbers of branches, ATMs, points of sale, and other forms of financial firms' penetration, especially in small rural communities; and high administrative costs, which tend to increase the fixed costs of extending loans and maintaining accounts. The authors have discussed this type of obstacles extensively both in this paper and elsewhere (see, for example, Allen and others 2012).

As an example at the country level, figure 3 shows the negative correlation between financial inclusion and a commonly used measure of banking system inefficiency: the ratio (in percent) of bank overhead costs to total assets. As expected, developed economies display the lowest ratios.

Another potential obstacle to financial inclusion relates to the concentration of the banking system. High levels of bank concentration may deter 
Figure 3. Financial Inclusion and Financial System Inefficiency

Percent of adults with a formal financial account

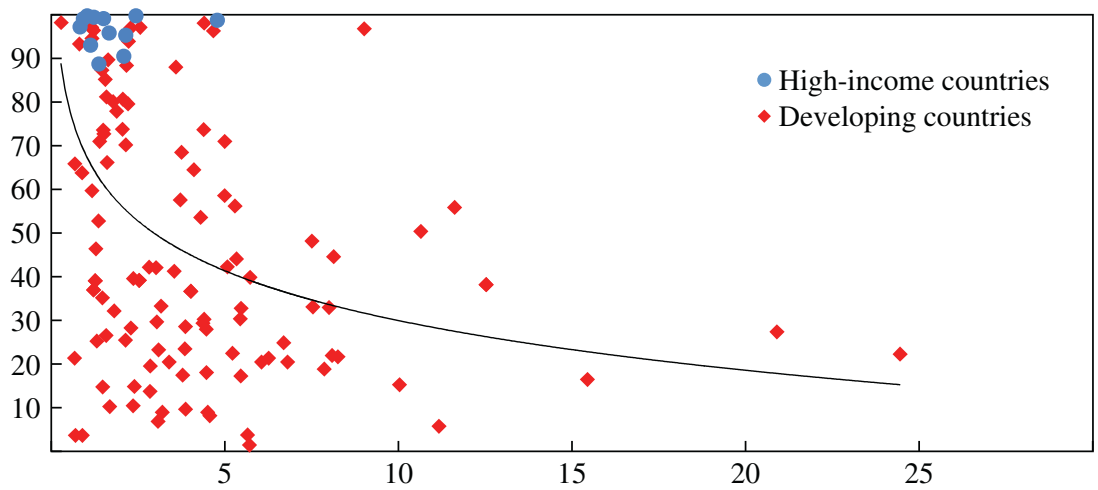

Bank overhead costs as a percent of total assets, 2009

Source: Based on Rojas-Suárez and Amado (forthcoming) using Global Findex data and Fitch's BankScope data.

a. The line in the figure is the best-fit line from a logarithmic regression in which the percent of adults with a formal financial account is the dependent variable.

banks from lending to individuals and to small and medium-size enterprises, since there are no competitive incentives to assess the quality of relatively riskier potential borrowers. Since the extension and repayment of bank loans are usually conducted through deposits in bank accounts, this argument could find support in a negative correlation between bank concentration and the share of adults with a formal financial account.

However, recent studies have argued that, in a given country, the relationship between bank concentration and financial inclusion is strongly affected by the quality of its institutions-the fourth category. (See, for example, Claessens 2005 and Rojas-Suárez and Amado forthcoming.) Financial systems can develop more fully and reach a larger segment of the population in countries with adequate observance and enforcement of the rule of law, political stability, and respect for creditors' and debtors' rights. In particular, when contracts between creditors and debtors are observed and enforced, depositors have a stronger incentive to entrust their savings to banks and other formal financial institutions. How do bank concentration and the quality of institutions interrelate to affect financial inclusion? In countries with weak institutions, where the enforcement of contracts is very difficult, the oligopolistic power arising from a highly concentrated banking system leads to greater discrimination against riskier borrowers (who tend to be low-income individuals and smaller firms), and financial 
inclusion suffers. Such discrimination is not as commonly seen in a more competitive banking system.

Figure 4 illustrates these relationships. The top panel shows a negative, but low, correlation between bank concentration, measured as the percentage of total system assets held by the country's three largest banks, and financial inclusion (the correlation coefficient is only -0.2). However, a very different picture arises in the bottom panel, where the bank concentration variable is adjusted by an additional variable measuring the quality of institutions. This variable, called "rule of law," is taken from the World Bank's Worldwide Governance Indicators and measures agents' confidence in and commitment to abiding by the rules of the society; the quality of contract enforcement, police, and the courts; and the likelihood of crime and violence. (I have rescaled the original variable to range from zero to 100.) The adjusted bank concentration variable is obtained simply by multiplying it by the rule of law variable.

Taken together, the two panels of figure 4 suggest that although bank concentration might impinge on financial inclusion directly, it exerts its most important effect through the quality of institutions. Two examples will clarify this point. First, it is clear from the top panel that the developed countries are distributed across the whole range of bank concentration, and thus little can be said about any differences in concentration between developed and developing countries (except that the negative relationship in the figure is driven by the latter). However, when the bank concentration variable is adjusted by the quality of institutions (bottom panel), most of the developed economies migrate toward the upper right corner of the scatterplot. For this group of countries as a whole, the relatively high level of institutional quality seems a more relevant factor than bank concentration for understanding the behavior of financial inclusion.

Second, consider Malaysia and Nicaragua. These two developing countries share similar ratios of bank concentration (top panel), but the quality of institutions is much higher in Malaysia than in Nicaragua. Therefore, when bank concentration is adjusted for institutional quality, Malaysia lies well to the right of Nicaragua. This is fully consistent with a higher level of financial inclusion in the former country than in the latter.

Although correlations such as these provide valuable insights, fully understanding the obstacles to financial inclusion requires a deeper analysis. The first column of my table 1 reports results of an ordinary least squares regression in which financial inclusion (as defined above) is the dependent variable. Consistent with the discussion above, I include as explanatory variables the five variables that appear on the horizontal axes 
Figure 4. Financial Inclusion and Bank Concentration, with and without Adjustment for Institutional Quality

\section{Unadjusted}

Percent of adults with a formal financial account

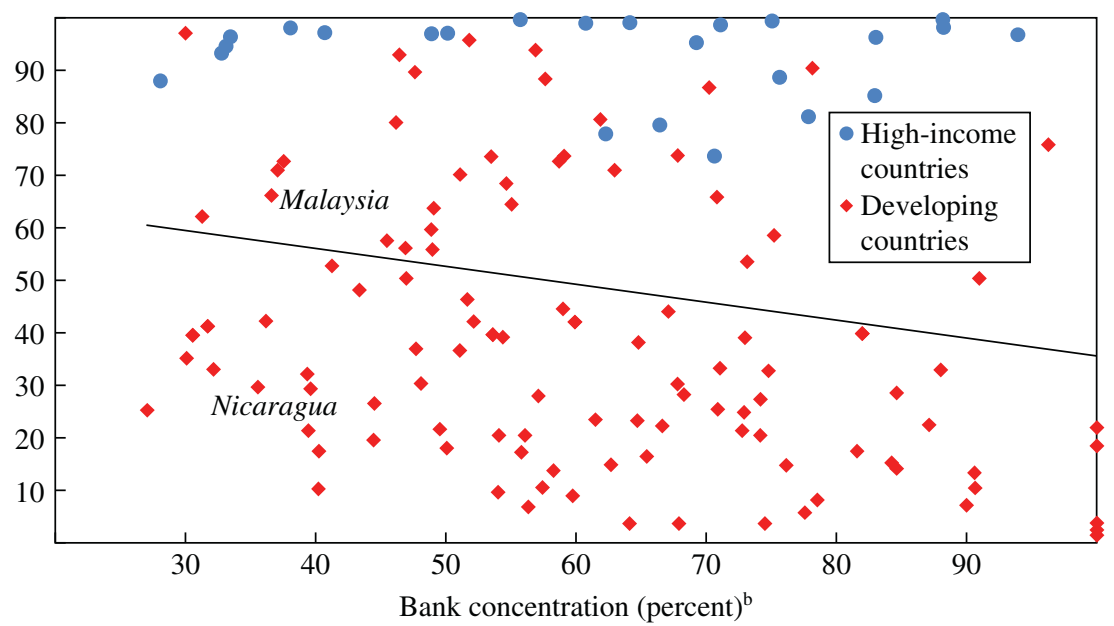

\section{Adjusted for institutional quality}

Percent of adults with a formal financial account

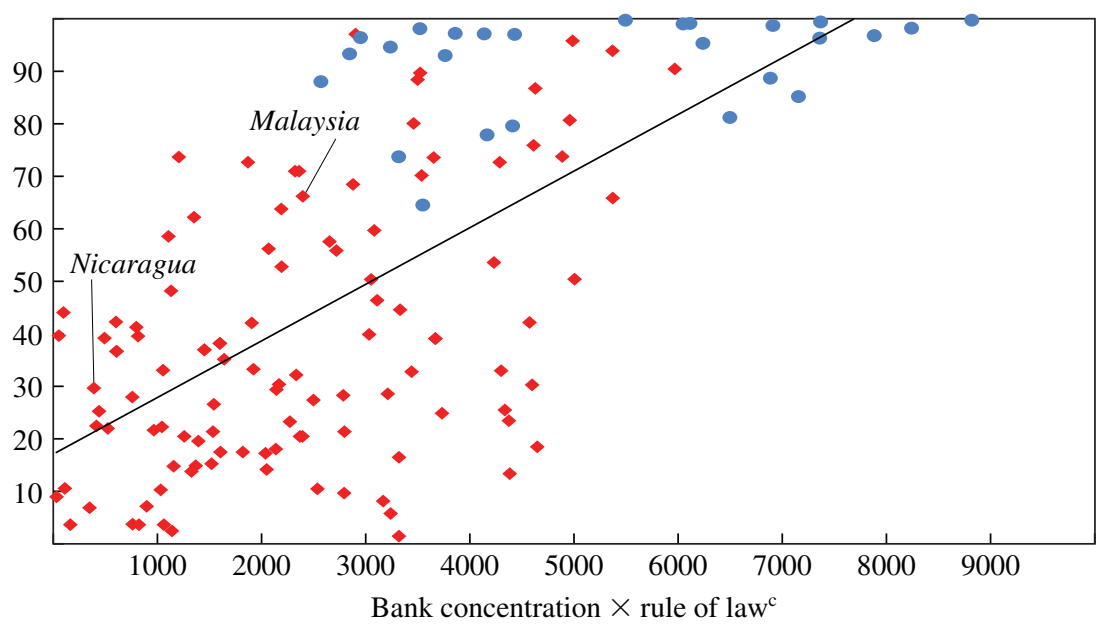

Source: Based on Rojas-Suárez and Amado (forthcoming) using data from Global Findex, Fitch's BankScope, and the World Bank.

a. The line in the figure is the best-fit line from a linear regression in which the percent of adults with a formal financial account is the dependent variable.

b. Share of total banking system assets held by the country's three largest banks.

c. The bank concentration variable in the top panel is multiplied by the rule of law measure from the World Bank's Worldwide Governance Indicators, rescaled from zero to 100 with higher values indicating greater strength of the rule of law. 
Table 1. Obstacles to Financial Inclusion: Implied Contributions from Regression Analysis ${ }^{\mathrm{a}}$

\begin{tabular}{|c|c|c|c|c|}
\hline \multirow[b]{2}{*}{ Independent variable } & \multirow[b]{2}{*}{$\begin{array}{l}\text { Regression } \\
\text { coefficient }\end{array}$} & \multicolumn{3}{|c|}{ Contribution $^{\mathrm{b}}$ (percentage points) } \\
\hline & & $\begin{array}{l}\text { Developed } \\
\text { economies }\end{array}$ & $\begin{array}{l}\text { Emerging } \\
\text { markets }\end{array}$ & $\begin{array}{c}\text { Other } \\
\text { developing } \\
\text { countries }\end{array}$ \\
\hline Social underdevelopment & $-36.29 * * *$ & -4.1 & -8.2 & -14.5 \\
\hline Bank concentration & $-0.29 * * *$ & -17.3 & -17.1 & -17.8 \\
\hline Bank concentration $\times$ rule of law & $0.004 * * *$ & 19.2 & 10.1 & 7.1 \\
\hline Volatility of inflation & $-3.11 * *$ & -2.9 & -4.9 & -4.0 \\
\hline $\begin{array}{l}\text { Ratio of bank overhead costs to } \\
\text { assets }\end{array}$ & -28.33 & -0.8 & -1.5 & -1.3 \\
\hline $\begin{array}{l}\text { Dummy for developed } \\
\text { economy }\end{array}$ & $37.94 * * *$ & 37.94 & 0 & 0 \\
\hline $\begin{array}{l}\text { Dummy for emerging market } \\
\text { Constant }\end{array}$ & $\begin{array}{l}10.61 * * \\
55.3^{* * * *}\end{array}$ & 0 & 10.61 & 0 \\
\hline
\end{tabular}

Source: Author's regressions.

a. The dependent variable is the percentage of the adult population with a bank account in a formal institution. Asterisks indicate statistical significance at the $* * * p<0.01$ or the $* * p<0.05$ level.

b. Measured as the regression coefficient for the indicated obstacle multiplied by that obstacle's average value in the indicated country group.

in figures 1 through 4 . In addition, the regression includes two dummy variables: the first identifies developed economies (again, those classified by the World Bank as high-income countries), and the second emerging markets (those classified as upper-middle-income countries). ${ }^{3}$ The regression was estimated for a sample of 116 countries.

Except for the coefficient on the bank overhead costs variable (which had a $p$ value of 0.18 ), all the estimated coefficients were statistically significant. The regression's $R^{2}$ was 0.8359 . For each country category, the last three columns of table 1 show the implied contributions of the various obstacles to financial inclusion, calculated by multiplying each variable's estimated coefficient by the variable's average value.

To illustrate how to interpret the table, consider the group "other developing countries." According to the table, if all factors affecting financial inclusion identified in the regression were absent, this group would enjoy, on average, a financial inclusion ratio (a share of adults holding a formal financial account) of 55 percent (the value of the constant). With the obstacles present, however, the predicted financial inclusion ratio for this group

3. The third group of countries (omitted in the regression) consists of all other developing countries (those classified as lower-middle-income and low-income countries). 
of countries reaches only 25 percent. Similarly, absent the identified obstacles, 66 percent of the adult population in emerging markets would have an account in a formal financial institution (the sum of the constant and the coefficient on the dummy for emerging markets). However, because of the obstacles, the predicted ratio is only 43 percent.

The most important conclusions to be drawn from the table are as follows. First, the degree of social development matters greatly. The low level of social development in developing countries on average, and to a lesser extent in emerging markets, hampers financial inclusion through both demand and supply factors. Second, only in the developed economies does the high level of institutional quality at least partly offset the adverse effect of bank concentration on financial inclusion (the sum of the implied contributions for the bank concentration variable alone and for the bank concentration $\times$ rule of law interaction is positive). In contrast, in emerging markets and other developing countries on average, low institutional quality cannot counteract the financial exclusion effects of bank concentration. Third, relative to the other factors, inflation volatility and banking inefficiencies play smaller roles as obstacles to financial inclusion.

My discussion here provides just a taste of the potential uses of the Global Findex database and is intended as a complement to the authors' analysis and their ongoing research. The authors are to be congratulated not only for this paper but for their rich research agenda on financial inclusion.

\section{REFERENCES FOR THE ROJAS-SUÁREZ COMMENT}

Allen, F., A. Demirgüç-Kunt, L. Klapper, and M. S. Martinez Peria. 2012. "The Foundations of Financial Inclusion: Understanding Ownership and Use of Financial Accounts." Policy Research Working Paper no. 6290. Washington: World Bank.

CAF Banco de Desarrollo de América Latina. 2011. Servicios Financieros para el Desarrollo: Promoviendo el Acceso en América Latina. Reporte de Economía y Desarrollo series. Caracas. publicaciones.caf.com/publicacion?id=1502.

Claessens, Stijn. 2005. "Universal Access to Financial Services: A Review of the Issues and Public Policy Objectives." Presented at the OECD-World Bank Fifth Services Experts Meeting, Paris (February).

Rojas-Suárez, Liliana, and Maria Alejandra Amado. Forthcoming. "Improving Access to Financial Services in Latin America: Policy Implications and Lessons from Worldwide Experiences." Washington: Center for Global Development.

Rojas-Suárez, Liliana, and Veronica Gonzales. 2010. "Access to Financial Services in Emerging Powers: Facts, Obstacles and Policy Implications." Paris: OECD Development Center (March) www.oecd.org/dev/pgd/45965165.pdf. 
GENERAL DISCUSSION While sympathetic to nonstandard approaches based on behavioral economics, information asymmetry, and the like, Christopher Carroll wondered whether the problem of financial inclusion might not be better addressed using the textbook approach that assumes perfect rationality. Looking at the list of countries with lowest participation in the banking sector-Argentina, Greece, and Italy, for example-was enough to suggest that many people around the world might have good reason not to hold bank accounts. Financial inclusion, Carroll thought, might turn out to be a good overall indicator of the quality of a country's institutions: low inclusion could correlate with the degree to which a society and its institutions are dysfunctional. If that was the case, efforts to increase the penetration of bank account ownership would not address the underlying cause of noninclusion.

Donald Kohn added that any deliberate effort to increase financial inclusion would surely bring in people who are not well educated and who lack familiarity with financial products. Encountering a sophisticated modern financial system for the first time, these individuals might not understand the risks they are taking or, worse, might suffer exploitation. Kohn observed that this danger was not limited to developing countries: the subprime episode in the United States could be viewed as an attempt at financial inclusion that ended badly. The U.S. response has been mainly to increase disclosure and transparency, but there have also been proposals aimed, in a sense, at disinclusion by restricting the types of financial instruments available to the general public. Kohn asked whether the authors had investigated whether the newly banked individuals in their samples actually understood what they were getting, particularly on the credit side, and whether their findings pointed to any measures that could be taken to improve their understanding.

David Romer, also following up on Carroll's comment, cited some specific findings in the paper that could be interpreted as rational behavior on the part of the nonincluded. For example, the paper reported that a large fraction of the nonincluded chose not to have a bank account because they had too little money to make it worthwhile. That seemed to Romer a plausibly rational response. Others said that they had a relative with a bank account, so that in effect they did have access to financial services even though they were counted as excluded. Still others cited long distances to the nearest bank branch as a reason for not having an account. Was that a market failure, or was it an equilibrium outcome? These questions needed to be sorted out, Romer argued, before useful policy interventions could be proposed. Romer also asked the authors to clarify their distinction 
between an individual's explicit choice of how much to save and the standard definition of the same individual's saving as simply income minus consumption.

Ricardo Reis suggested that the present degree of inclusion in the banking system in some countries might actually be too high, in the sense that many people have bank accounts but lack access to other financial services that are arguably more important to their welfare, such as insurance against catastrophic shocks and vehicles for retirement saving.

Following up on Rojas-Suárez's discussion and Kohn's comment, Reis reminded the Panel that in the United States for much of the 19th century, a bank was an extremely risky place to keep one's savings: the history of banks in that largely unregulated era was rife with fraud. If bank regulation today in some developing countries is comparably weak, that argued against pushing for greater inclusion. On a similar note, Reis observed that, according to the paper, 78 percent of Greeks still had bank accounts in 2011, well into that country's financial crisis. That indicated to him a failure on the account holders' part to appreciate the risks they were taking.

For Benjamin Friedman, one of the paper's most interesting findings was that many people lack bank accounts because they do not trust the banks. He suspected, however, that their distrust could arise for different reasons. One might be the fear of bank fraud or recklessness that Reis had mentioned, but another might be fear of government expropriation: many Cambodians, for example, are wary of banks because they remember when the Pol Pot regime closed all the country's banks overnight and simply expropriated all the accounts. An entirely different potential motivation was the fear that the bank would not keep one's affairs secret. One needed to distinguish among these different reasons before deciding what sort of policy intervention was called for.

Michael Klein pointed out that people might choose to remain unbanked for transactional reasons as well as because of lack of savings or for other reasons. In countries where only cash is widely accepted, the transactionsrelated features of a bank account—checkwriting and debit cards, for example-would have little value.

Justin Wolfers remarked that the literature on financial access seemed to take it as given that financial access was a good thing, and indeed, to those who have it, it clearly is. But its benefits might be less obvious to those who have never had it. Wolfers also identified what he saw as a possible problem with the authors' empirical strategy. The paper claimed to be measuring access to financial services, meaning the ability to use those 
services if one wanted to, but what it really measured was an equilibrium quantity: those who, given the equilibrium price of holding a bank account, and taking into account all costs, actually used one. Just as not everyone who has access to spinach at the supermarket eats spinach, so, too, not everyone who has access to banking services opens a bank account.

Responding to the discussion, Leora Klapper answered Romer's question by saying that she and her coauthor were interested not in the quantity of saving as such but in the behavioral decision to save: what people did with the money that they were deliberately putting aside for a specific purpose, such as for a large purchase or for retirement. What the authors found was that these savings were typically placed in informal ROSCAs (rotating savings and credit associations) or under the mattress. Since the former are plagued by fraud and the latter is extremely unsafe, it seemed to the authors natural to suppose that a formal bank account, or at least a lockbox at a bank, was a better place to hold that money. Klapper also noted that in some countries such as Bangladesh, microfinance institutions are important sources of formal savings and credit, used by many people who do not have bank accounts.

Klapper also acknowledged that the histories of some countries, including some in Eastern Europe, provided their citizens ample reason to be distrustful of banks, and that lack of understanding of bank terms and conditions could result in exploitation or cause people to make poor use of their accounts. As an example, the failure of small savers to understand the concept of a minimum balance often leads to their savings being eroded. Klapper therefore emphasized that greater financial literacy was a necessary complement to sound regulation and consumer protection: it could contribute not only to broadening the use of safer financial services, but also to building trust in the financial system in countries with a history of financial scandal and expropriation.

Aslı Demirgüç-Kunt sought to clarify that the paper was not claiming or assuming that more people around the world should have bank accounts. Rather, she and Klapper were interested in identifying the perceived barriers to holding bank accounts among those who might want to use them. They believed that if market failures are indeed preventing broader access to bank accounts, the result was to limit people's ability to save for education or for other worthwhile purposes, and to limit businesses' access to capital for growth and expansion. In presenting their findings to policymakers, they took pains to emphasize the importance of responsible access. It was true that a majority of their respondents chose not to hold bank accounts because they did not have enough money to 
make it worthwhile, and some fraction of these presumably would see no need for an account even if they had more money. But a large fraction of the rest-30 percent of the total sample-identified other barriers such as high costs, remoteness, or instruments whose design does not conform with the potential user's religious beliefs. These were issues that a wellcrafted policy might be able to remedy. 